\title{
Synthesis and Antitumor Activity of 20(S)-Camptothecin Derivatives: Carbamate-Linked, Water-Soluble Derivatives of 7-Ethyl-10-hydroxycamptothecin ${ }^{1)}$
}

\author{
Seigo Sawada, ${ }^{*, a}$ Satoru Okajima, ${ }^{a}$ Ritsuo Aiyama,${ }^{a}$ Ken-ichiro Nokata,,${ }^{a}$ Tomio Furuta, ${ }^{a}$ Teruo Yokokura,,${ }^{a}$ Eiichi \\ Sugino, ${ }^{b}$ Kentaro YamaGUCHI ${ }^{c}$ and Tadashi MIYASAKA ${ }^{c}$ \\ Yakult Institute for Microbiological Research, ${ }^{a}$ Yaho 1796, Kunitachi-shi, Tokyo 186, Japan. Faculty of Pharmacy and Pharmaceutical Sciences, Fukuyama \\ University, ${ }^{b}$ Fukuyama-shi, Fukuyama, Japan and School of Pharmaceutical Sciences, Showa University, ${ }^{c}$ Hatanodai, 1-5-8, Shinagawa-ku, Tokyo 142, \\ Japan. Received December 20, 1990
}

Novel 36 derivatives (6), bonding the phenolic hydroxyl group of 7-ethyl-10-hydroxycamptothecin (4) with diamines through a monocarbamate linkage, were synthesized and their antitumor activity was evaluated in vivo. The derivatives were soluble in water as their $\mathrm{HCl}$ salts with the $\mathrm{E}$ lactone ring intact and exhibited significant antitumor activity. One of the derivatives, 6-27 showed excellent activity against L1210 leukemia and other murine tumors. The structure of its hydrochloride trihydrate (CPT-11) was determined by spectroscopic and crystallographic methods.

Keywords 20(S)-camptothecin; 7-ethyl-10-hydroxycamptothecin; carbamate; CPT-11; X-ray crystallography; antitumor activity

$20(S)$-Camptothecin $(1$, Chart 1$)$ is an alkaloid which was first isolated from Camptotheca acuminata (Nyssaceae) by Wall and his co-workers in $1966{ }^{2)}$ It has attracted much attention because of its significant inhibitory activity towards L1210 leukemia in mice and Walker 256 sarcoma in rats. The clinical trials of this alkaloid were carried out using its water soluble sodium salt, in which the E-lactone ring was cleaved by sodium hydroxide, but its severe toxicity to bone marrow and bladder ruled out the salt for the cancer treatment. ${ }^{3)}$

Camptothecin (lactone) administered in suspension exhibited a satisfactory high cytotoxic activity towards L1210 leukemia in vivo whereas the salt in aqueous solution has rather low activity. The lactone moiety of the alkaloid including the 20-hydroxyl group was said to be the responsible group for the activity ${ }^{3)}$ and the salt was assumed to lactonize in vivo although detailed behavior of the salt was not yet clear.

We describe here the synthesis of derivatives of 7-ethyl10 -hydroxycamptothecin (4), whose 10-hydroxyl group is connected with a hydrophilic functional side chain through a carbamate linkage, and the evaluation of their antitumor activity. We already reported the significant antitumor activity of the compound obtained herein, 6-27 (its hydrochloride trihydrate; CPT-11), toward various tomor systems ${ }^{4)}$ and CPT-11 is now under phase II of clinical trials in Japan. ${ }^{5}$

\section{Chemistry}

We reported the synthesis and antitumor activity of various 7-C-substituted and the A-ring modified derivatives starting from 20(S)-camptothecin. ${ }^{6}$ ) Compound 4, which has a phenolic hydroxyl group as a foothold for hydrophilic modifications, was selected as the starting material because of its good therapeutic index [TI: optimal dose/minimum effective dose, 4: $\mathrm{TI}=50,1$ : $\mathrm{TI}=3.1, \mathrm{~L} 1210$ in mice $]$. Compound 4 is also a potent inhibitor of deoxyribonucleic acid (DNA) topoisomerase I. ${ }^{7 c)}$

Synthesis of $\mathbf{4}$ was depicted in Chart 1. Hydrogen peroxide was added dropwise to an ice-cold solution of 1 in sulfuric acid in the presence of ferrous sulfate and freshly distilled propionaldehyde. From the reaction mixture 2 was obtained in a good yield. Compound 2 was converted into its $\mathrm{N}$-oxide
(3). The $N$-oxide was then dissolved in dioxane containing equimolar amounts of sulfuric acid, and the mixture was irradiated with a high pressure $\mathrm{Hg}$ lamp $(450 \mathrm{~W})$ through a Pyrex filter to afford the 10-hydroxyl compound (4) in $30-35 \%$ overall yields. ${ }^{11}$

Since the introduction of a bulky substituent either in the A or in the B-ring of camptothecin weakened or completely vanished its activity, a hydrophilic side chain is bound to the phenolic hydroxyl group of $\mathbf{4}$ through such linkages as organic or inorganic esters, glycosides, which seemed to be susceptible to enzymatical hydrolysis in vivo. We at first attempted to synthesize the derivatives having an amino acid group as the side chain, but these carboxyester derivatives decomposed to the starting phenol during purification. We selected more stable carbamate linkage, which was hydrolyzable in vivo. ${ }^{8)}$ Furthermore, the fact ${ }^{9)}$ that the linkage is selectively hydrolyzed in some tumor cells attracted our interest for a homing device.

A series of carbamate derivatives (6) were prepared either by the reaction of chlorocarbonyl derivatives of diamines with 4 in pyridine, or by the reaction of diamines with chlorocarbonyloxy compound 5 , which was obtained in a good yield by the treatment of 4 with phosgen in the presence of triethylamine (Chart 1 and Table I). In this case, the phenol 4 was yielded in addition to 6 . The secondary-secondary or secondary-tertiary diamines used in this work were mostly commercially available, but acyclic diamines and 4-dialkylaminopiperidines were prepared according to the reported methods. ${ }^{10)}$ The yields were fairly low in the reaction of $\mathbf{4}$ with isocyanates and the reactions of 5 with primary-secondary or tertiary diamines and amino acid esters, since the products seemed to be hydrolyzed via a deprotonation-elimination mechanism in the basic reaction media.

CPT-11, hydrochloride trihydrate of 6-27, was chosen for the determination of its structure. CPT-11 was obtained as slightly pale yellow needles or crystalline powder by crystallization from water and the compound has three molecules of water of crystallization suggested by its elemental analysis. The crystals were stable to heat $\left(100^{\circ} \mathrm{C}\right.$ for a week) but some degradation was observed by exposure to visible light. The salt dissolved in water into a clear acidic solution ( $\mathrm{pH} 4$ in $2 \%$ solution) in which the compound was 
<smiles>CCc1c2c([n+]([O-])c3ccccc13)-c1cc3c(c(=O)n1C2)COC(=O)[C@@]3(O)CC</smiles>

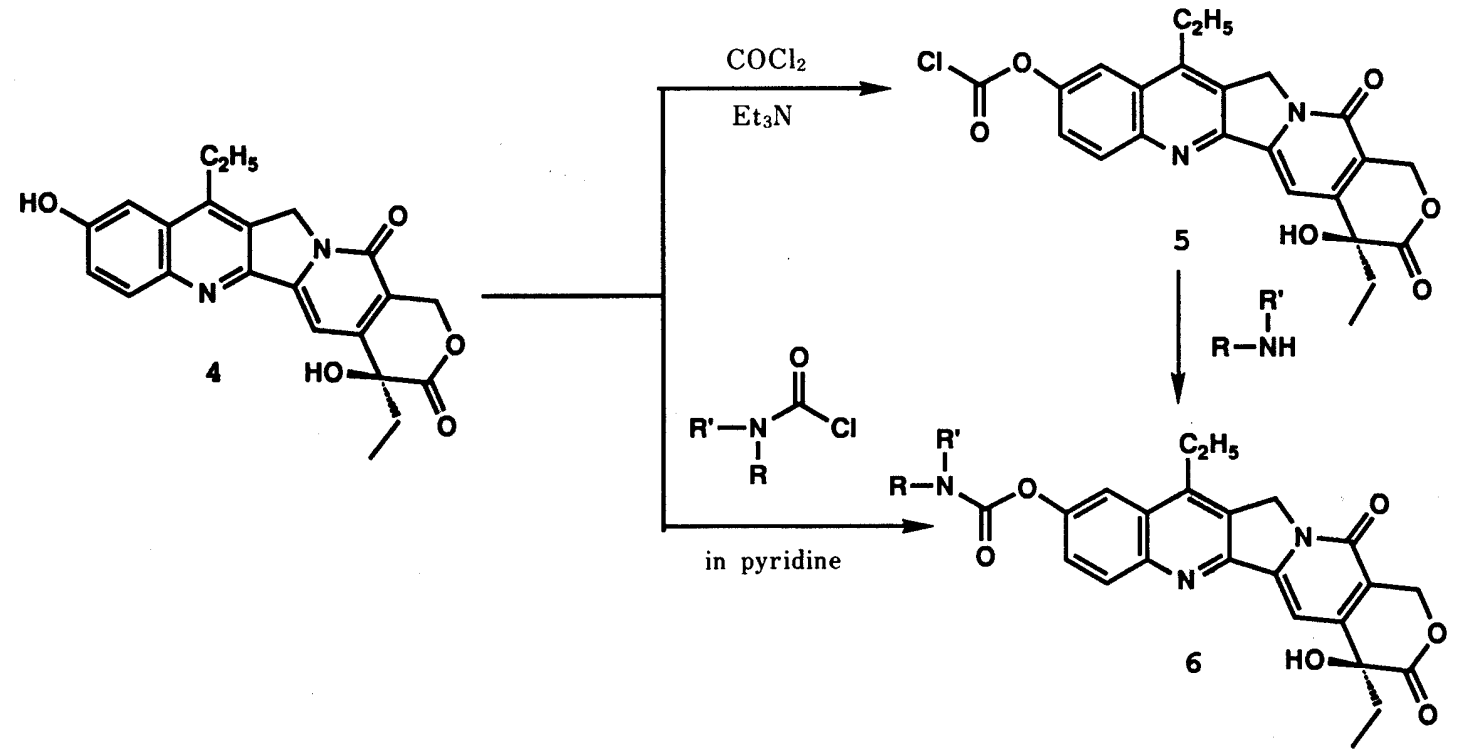

Chart 1
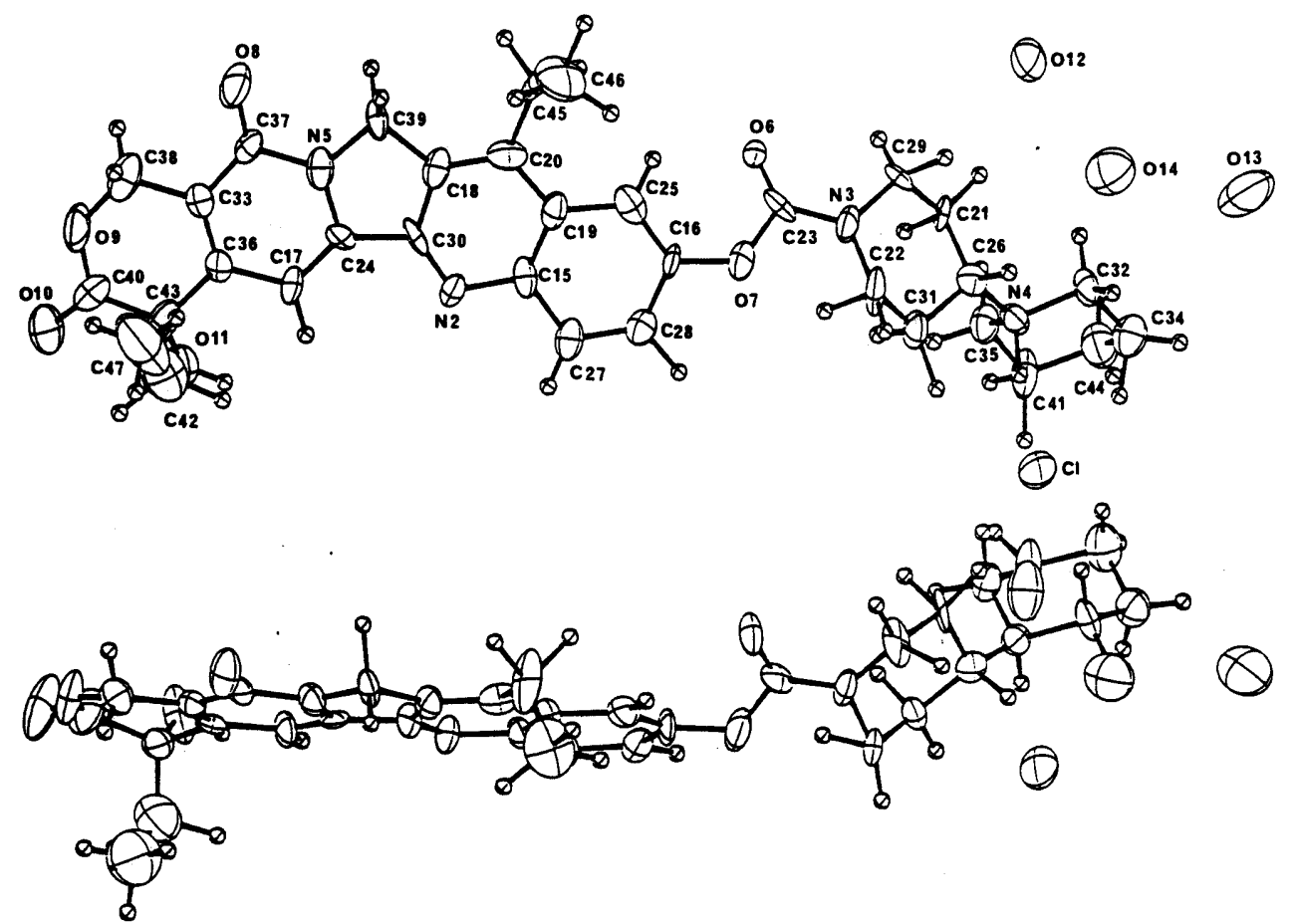

Fig. 1. ORTEP Drawings of CPT-11 from a Different View

stable $\left(100^{\circ} \mathrm{C}\right.$ for $\left.16 \mathrm{~h}\right)$ under the interception of light. The full assignments of proton nuclear magnetic resonance $\left({ }^{1} \mathrm{H}-\mathrm{NMR}\right)$ and carbon-13 nuclear magnetic resonance $\left({ }^{13} \mathrm{C}-\mathrm{NMR}\right)$ spectroscopy by homo and hetero correlation spectroscopy (COSY) and correlation spectroscopy via long range coupling (COLOC) methods, and also other spectroscopic data, were met in Experimental.

The proposed structure was confirmed by the single crystal X-ray crystallographic study. The observed cell parameters for a crystal of CPT-11 $(0.35 \times 0.05 \times 0.20 \mathrm{~mm})$ recrystallized from aqueous acetonitrile were as follows: $\mathrm{C}_{33} \mathrm{H}_{38} \mathrm{~N}_{4} \mathrm{O}_{6} \cdot \mathrm{HCl} \cdot 3 \mathrm{H}_{2} \mathrm{O}, M_{\mathrm{w}}=677.19$, orthorhombic, 
TABLE I. Antitumor Activity of the Camptothecin Derivatives on L1210 Leukemia in CDF 1 Mice

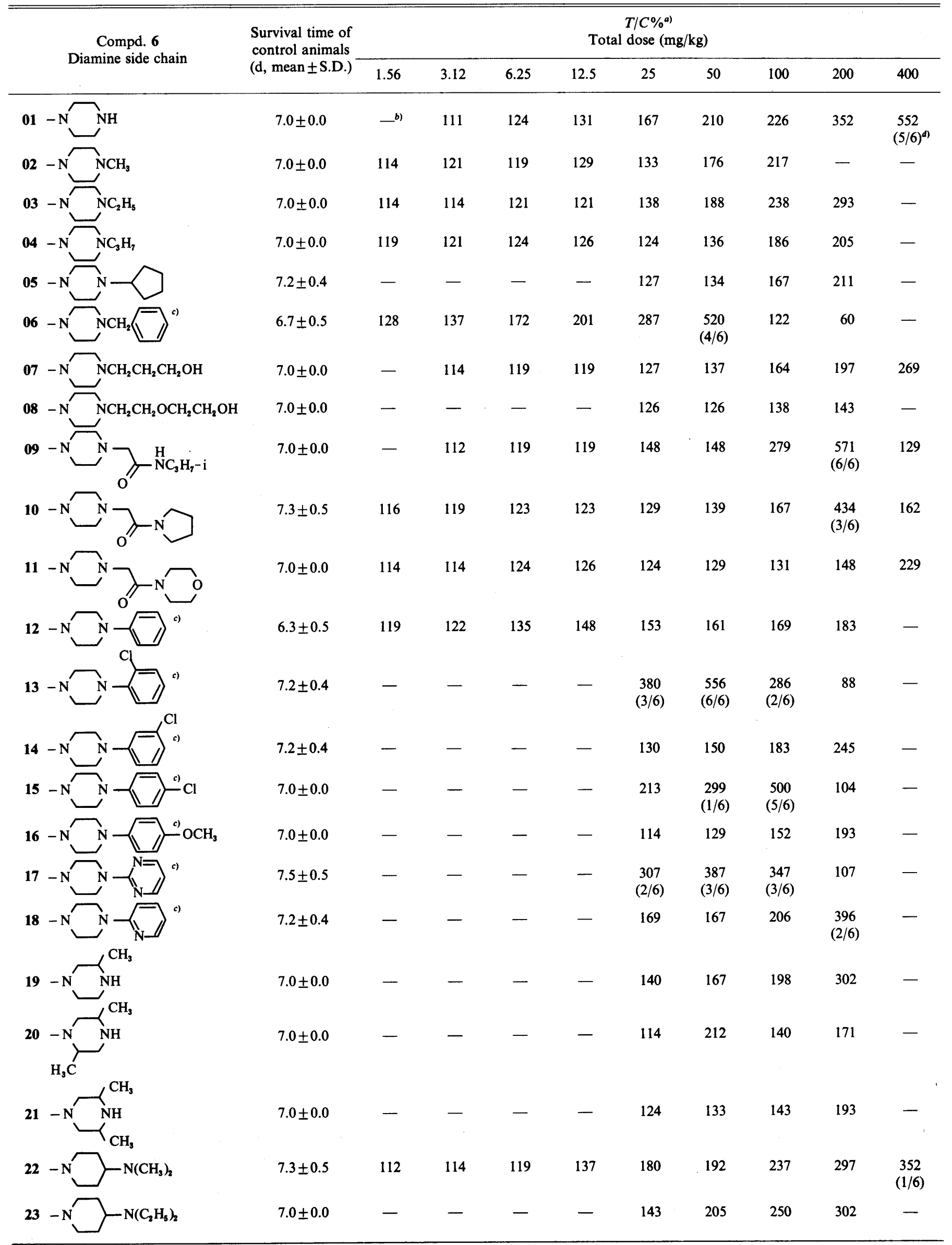


TABLE I. (continued)

\begin{tabular}{|c|c|c|c|c|c|c|c|c|c|c|c|}
\hline \multirow{2}{*}{\multicolumn{2}{|c|}{$\begin{array}{c}\text { Compd. } 6 \\
\text { Diamine side chain }\end{array}$}} & \multirow{2}{*}{$\begin{array}{l}\text { Survival time of } \\
\text { control animals } \\
\text { (d, mean } \pm \text { S.D.) }\end{array}$} & \multicolumn{9}{|c|}{$\begin{array}{c}T / C \%{ }^{a)} \\
\text { Total dose }(\mathrm{mg} / \mathrm{kg})\end{array}$} \\
\hline & & & 1.56 & 3.12 & 6.25 & 12.5 & 25 & 50 & 100 & 200 & 400 \\
\hline 24 & $-\mathrm{N}\left(\mathrm{C}_{3} \mathrm{H}_{7}\right)_{2}$ & $7.0 \pm 0.0$ & - & - & - & - & 150 & 205 & 245 & $\begin{array}{c}312 \\
(1 / 6)\end{array}$ & - \\
\hline 25 & $-\mathrm{N}\left(\mathrm{C}_{4} \mathrm{H}_{0}\right)_{2}$ & $7.0 \pm 0.0$ & - & - & - & - & 154 & 207 & 229 & $\begin{array}{c}340 \\
(1 / 6)\end{array}$ & - \\
\hline 26 & & $7.3 \pm 0.5$ & 112 & 121 & 148 & 153 & 199 & 224 & 274 & $\begin{array}{c}463 \\
(4 / 6)\end{array}$ & $\begin{array}{c}495 \\
(4 / 6)\end{array}$ \\
\hline 27 & & $7.0 \pm 0.0$ & - & 119 & 129 & 167 & 226 & 274 & $\begin{array}{c}571 \\
(6 / 6)\end{array}$ & $\begin{array}{c}571 \\
(6 / 6)\end{array}$ & 124 \\
\hline 28 & & $8.0 \pm 0.0$ & 104 & 113 & 119 & 117 & 125 & 160 & 192 & $\begin{array}{c}338 \\
(2 / 6)\end{array}$ & 81 \\
\hline 29 & $\mathrm{NCH}_{3}$ & $6.3 \pm 0.5$ & 100 & 98 & 127 & 130 & 130 & 132 & 148 & 178 & - \\
\hline 30 & & $7.0 \pm 0.0$ & - & - & - & - & 117 & 114 & 119 & 126 & - \\
\hline 31 & & $7.0 \pm 0.0$ & - & - & - & - & 129 & 155 & 198 & $\begin{array}{l}298 \\
(1 / 6)\end{array}$ & - \\
\hline 32 & $\begin{array}{l}-\mathrm{NCH}_{2} \mathrm{CH}_{2} \mathrm{~N}\left(\mathrm{CH}_{3}\right)_{2} \\
\mathrm{CH}_{3}\end{array}$ & $7.0 \pm 0.0$ & 124 & 129 & 124 & 133 & 145 & 226 & $\begin{array}{c}310 \\
(1 / 6)\end{array}$ & $\begin{array}{l}495 \\
(5 / 6)\end{array}$ & 90 \\
\hline & $-\mathrm{NCH}_{2} \mathrm{C}_{2} \mathrm{H}_{5}$ & $7.0 \pm 0.0$ & - & - & - & - & 114 & 157 & 183 & 236 & - \\
\hline 34 & $-\mathrm{NCH}_{2} \mathrm{CH}_{2} \mathrm{~N}\left(\mathrm{C}_{2} \mathrm{H}_{5}\right)_{2}$ & $7.3 \pm 0.5$ & - & - & 110 & 110 & 121 & 142 & 176 & 201 & - \\
\hline 35 & $-\mathrm{NCH}_{2} \mathrm{CH}_{2} \mathrm{~N}\left(\mathrm{C}_{2} \mathrm{H}_{5}\right)_{2}$ & $7.5 \pm 0.5$ & 109 & 118 & 118 & 116 & 113 & 127 & 153 & 180 & - \\
\hline 36 & $-\mathrm{NCH}_{2} \mathrm{CH}_{2} \mathrm{~N}\left(\mathrm{C}_{2} \mathrm{H}_{5}\right)_{2}$ & $7.5 \pm 0.5$ & - & - & 102 & 104 & 104 & 116 & 127 & 144 & - \\
\hline
\end{tabular}

a) $T / C \%=($ mean survival time of the tested animals $) /($ mean survival time of the control animals $) \times 100 . \quad b$ ) Not tested. c) Administered in suspension. d) Number of cured mice/number of mice tested.

$P 2_{1} 2_{1} 2_{1}, a=12.154(5), b=42.847(5), c=6.422(5)(\AA)$, $V=3344(3) \AA^{3}, \quad Z=4, \quad D_{\mathrm{x}}=1.345 \mathrm{Mgm}^{-3}, \quad \lambda\left(\mathrm{CuK} \alpha_{1}\right)=$ $1.54050 \AA, \mu=1.521 \mathrm{~mm}^{-1}, F(000)=1440, T=295 \mathrm{~K}$. The structures were solved by the direct method, and refined by full-matrix least-squares calculations assuming anisotropic temperature factors for nonhydrogen atoms and isotropic ones for hydrogen atoms. Final $R=0.083, R_{\mathrm{w}}=0.080$ for 1724 reflections above $3 \sigma(F)$. Atomic coordinates and isotopic thermal parameters are shown in Table IV.

As illustrated in Fig. 1, the structure of the compound consists of a 7-ethylcamptothecin skeleton with a piperidinopiperidine side chain and the presence of a chlorine atom and three oxygen atoms demonstrated the hydrochloride trihydrate structure. The side chain has an intertwisted structure and the $\mathrm{E}$ ring lactone moiety constitutes a quasi chair form and the ethyl group at $\mathrm{C}_{20}$ installs in quasi axial and the free hydroxyl group is equatorial, of which conformation was similar to that of 20 $O$-iodoacetylcamptothecin. ${ }^{11)}$

The importance of the $20(S)$-geometry of camptotheca alkaloids for antitumor activity has been demonstrated in comparison with its antipode in the animal tumor system. ${ }^{12)}$ We examined the optical purity of compound 6-27 by NMR spectrum using a shift reagent, \{tris-[3- (heptafluoropropylhydroxymethylene)-(+)-camphorate]europium (III)\}. The hydrogen at the 9-position of compound 6-27 synthesized starting from 20(S)-camptothecin, has one doublet at $\delta 7.78$, whereas the racemic 6-27, synthesized according to Wall's report, ${ }^{13)}$ showed two doublets at $\delta 7.78$ and $\delta 7.80 \mathrm{ppm}$ arising from $S$ and $R$ form, respectively. A chiral stationary phase high performance liquid chromatography (HPLC) separation of CPT-11 also indicates that there was no detectable $R$-form.

\section{Results and Discussion}

The activity of novel 36 derivatives synthesized in this work was estimated toward L1210 leukemia in mice (Table I). The test was carried out using a clear aqueous solution of their $\mathrm{HCl}$ salt, but the compounds $6-06,13-17$, and 18 were administered in suspension because of the low solubility of the $\mathrm{HCl}$ salts of these compounds. The $\mathrm{HCl}$ salt of 6-23 gave compound 4 as a precipitate in the aqueous solution. All the water soluble derivatives exhibited the activity $[T / C \%>125$ (the percentage of the mean survival time of the treated and that of the untreated group)]. Cured mice were observed in 9 derivatives, 6-01, $09,10,22,24-27$, and 31 at a total dose of 100 to $400 \mathrm{mg} / \mathrm{kg}$. 
TABLE II. Antitumor Activity of the Selected Derivatives against Acites Tumors

\begin{tabular}{|c|c|c|c|c|}
\hline \multirow{2}{*}{ Tumor system } & \multirow{2}{*}{$\begin{array}{l}\text { Total dose } \\
(\mathrm{mg} / \mathrm{kg})\end{array}$} & \multicolumn{3}{|c|}{$T / C \%^{a)}$} \\
\hline & & 6-01 & 6-09 & 6-27 \\
\hline P338 leukemia & 3.12 & 141 & 111 & 144 \\
\hline i.p.-i.p. & 6.25 & 156 & 115 & 165 \\
\hline \multirow[t]{6}{*}{$q 4 d$ d $1-9$} & 12.5 & 173 & 126 & 194 \\
\hline & 25.0 & 187 & 146 & 235 \\
\hline & 50.0 & 211 & 246 & 281 \\
\hline & 100.0 & 265 & $393(4 / 6)^{b)}$ & $343(1 / 6)$ \\
\hline & 200.0 & $404(4 / 6)$ & $404(4 / 6)$ & $428(3 / 6)$ \\
\hline & 400.0 & $444(6 / 6)$ & 74 & $333(4 / 6)$ \\
\hline \multicolumn{5}{|c|}{ Survival time of control animals $(\mathrm{d}, 9.0 \pm 0.0)$} \\
\hline L1210 leukemia & 6.25 & 103 & 98 & 98 \\
\hline i.p. $-p . o$ & 12.5 & 98 & 100 & 103 \\
\hline \multirow[t]{5}{*}{$\mathrm{q} 4 \mathrm{~d} d \mathrm{~d}-9$} & 25.0 & 98 & 100 & 105 \\
\hline & 50.0 & 98 & 114 & 119 \\
\hline & 100.0 & 98 & 132 & 151 \\
\hline & 200.0 & 98 & 160 & 199 \\
\hline & 400.0 & 103 & 192 & 240 \\
\hline \multicolumn{5}{|c|}{ Survival time of control animals $(\mathrm{d}, 7.3 \pm 0.0)$} \\
\hline B16 melanoma & 3.12 & 104 & 107 & 99 \\
\hline i.p.-i.p. & 6.25 & 104 & 101 & 109 \\
\hline \multirow[t]{6}{*}{ qd d $\mathrm{l}-17$} & 12.5 & 109 & 107 & 111 \\
\hline & 25.0 & 107 & 106 & 117 \\
\hline & 50.0 & 121 & 103 & 138 \\
\hline & 100.0 & 139 & 113 & 155 \\
\hline & 200.0 & 153 & 144 & 158 \\
\hline & 400.0 & 179 & 171 & $215(2 / 6)$ \\
\hline \multicolumn{5}{|c|}{ Survival time of control animals $(\mathrm{d}, 22.5 \pm 1.5)$} \\
\hline B16 melanoma & 12.5 & 107 & $11 \overline{1}$ & 109 \\
\hline i.p.-i.v. & 25.0 & 112 & 111 & 112 \\
\hline \multirow[t]{4}{*}{ q4d d $1-17$} & 50.0 & 115 & 117 & 121 \\
\hline & 100.0 & 121 & 118 & 123 \\
\hline & 200.0 & 121 & 118 & 132 \\
\hline & 400.0 & 125 & 117 & 143 \\
\hline Survival & ne of contro & animals $(d$ & $2.5 \pm 1.5)$ & \\
\hline
\end{tabular}

a) $T / C \%=$ (mean survival time of the tested animals)/(mean survival time of the control animals) $\times 100$. b) Number of cured mice/number of mice treated.

We selected three water-soluble derivatives, 6-01, 09, and 27 for further evaluation of their activity of several tumor systems (Tables II and III). The compounds showed good activity in these tumor systems, but compounds 6-01 and 09 were inactive by oral administrations (p.o.) and on B16 melanoma by intravenous (i.v.) administration. Compound 6-27 had satisfactory activity in all systems examined.

The highlighting of the carbamate linkage is susceptible to hydrolysis mainly in serum and liver, in this case, that is, CPT-11 was gradually converted into compound 4 . On the administration of CPT-11 in mice, a rather higher concentration of 4 is sustained for a longer term than by the administration of the sodium salt of 4 in serum and some tissues. ${ }^{14)}$ The compound derived the excellent activity because Camptotheca alkaloids were said to exert the activity time-dependently. ${ }^{7 b)}$

Among the 36 derivatives, there were great differences in their activity depending on the structure of the side chains which held the diamine-monocarbamate moiety. The diamine side chain furnishes the derivatives with a more lipophilic property and also endows a specific structure as the substrate for the hydrolyzing enzyme. Characterization of the enzyme is now being undergone. We intend to measure the hydrolysis profile of the enzyme on derivatives
TABLE III. Antitumor Activity of the Selected Derivatives against Solid Tumors

\begin{tabular}{|c|c|c|c|c|}
\hline \multirow{2}{*}{ Tumor system } & \multirow{2}{*}{$\begin{array}{l}\text { Total dose } \\
(\mathrm{mg} / \mathrm{kg})\end{array}$} & \multicolumn{3}{|c|}{ I.R. $\%^{a)}$} \\
\hline & & 6-01 & 6-09 & 6-27 \\
\hline \multirow{5}{*}{$\begin{array}{l}\text { Sarcoma } 180 \\
\text { s.c.-i.v. } \\
\text { q4d d } 1-9\end{array}$} & 50.0 & 27.8 & 38.5 & $59.0^{b, c)}$ \\
\hline & 100.0 & 40.0 & 59.0 & $74.4^{d)}$ \\
\hline & 200.0 & $72.2^{d)}$ & $69.2^{c)}$ & $92.3^{d)}$ \\
\hline & 400.0 & $94.8^{d)}$ & $89.7^{d)}$ & -e) \\
\hline & & & $(3 / 10)^{f)}$ & \\
\hline \multicolumn{5}{|c|}{ Tumor weight of control animals $(\mathrm{g}, 1.15 \pm 0.7)$} \\
\hline Sarcoma 180 & 50.0 & 7.9 & 11.4 & 14.3 \\
\hline s.c.-p.o. & 100.0 & 0 & $72.9^{d)}$ & $59.8^{c)}$ \\
\hline$q 4 d d 1-9$ & 200.0 & 29.3 & $69.3^{d)}$ & $80.0^{d)}$ \\
\hline & 400.0 & 26.4 & $77.9^{d)}$ & $90.7^{d)}$ \\
\hline \multicolumn{5}{|c|}{ Tumor weight of control animals $(\mathrm{g}, 1.40 \pm 0.82)$} \\
\hline Meth A & 50.0 & 3.8 & $4 \overline{5} .1$ & $51.0^{d)}$ \\
\hline s.c.-i.v. & 100.0 & 31.3 & $49.1^{d)}$ & $74.0^{d)}$ \\
\hline$q 4 d d 1-9$ & 200.0 & $51.8^{d)}$ & $53.9^{d)}$ & $90.3^{d)}$ \\
\hline & 400.0 & $86.3^{d)}$ & $67.5^{d)}$ & $98.5^{\mathrm{d})}$ \\
\hline \multicolumn{5}{|c|}{ Tumor weight of control animals $(\mathrm{g}, 2.06 \pm 0.8)$} \\
\hline Meth A & 50.0 & 24.2 & $38.2^{c}$ & $37.6^{c)}$ \\
\hline s.c.-i.v. & 100.0 & 27.9 & $33.9^{c)}$ & $46.1^{d)}$ \\
\hline \multirow[t]{5}{*}{$\mathrm{q} 4 \mathrm{~d}$ d $1-9$} & 200.0 & 26.1 & $52.7^{d)}$ & $73.3^{d)}$ \\
\hline & 400.0 & 36.4 & $60.6^{d)}$ & $90.3^{d)}$ \\
\hline & 600.0 & - & - & $94.5^{d)}$ \\
\hline & 800.0 & - & - & $97.3^{d)}$ \\
\hline & 1000.0 & - & - & $99.2^{d)}$ \\
\hline Tumor & eight of $\mathrm{cc}$ & inıma & $55 \pm 0.4)$ & \\
\hline
\end{tabular}

a) Inhibition rate (I.R.)\%=

$$
\left(1-\frac{\text { mean tumor weight of tested animals }}{\text { mean tumor weight of control animals }}\right) \times 100 \text {. }
$$

b) Statistical significance of difference from control, $c$ ) $p<0.01, d$ ) $p<0.001$ (Student's $t$ test). e) Not tested. $f$ ) Number of tumor-free mice/number of mice tested.

synthesized herein to understand the structure-activity relationships.

In conclusion, we synthesized here the $\mathrm{E}$ ring intact water-soluble derivatives of compound 4 by connecting with diamines through carbamate linkage and evaluated the compound in mice tumor screens. CPT-11, hydrochloride trihydrate of $\mathbf{6 - 2 7}$, was found as a potential nominee for a new anticancer agent.

A synthesis of other types of water-soluble derivatives of compound 4 on this line is now under progress. Synthesis and activity of sulfates, phosphates and glycosides of 4 will be published elsewhere.

\section{Experimental}

Melting points (with decomposition) were uncorrected. Ultraviolet (UV) spectra were taken with a Shimadzu UV-240 spectrophotometer. ${ }^{1} \mathrm{H}$ - and ${ }^{13} \mathrm{C}-\mathrm{NMR}$ spectra were recorded on a JEOL GX-400 $(400 \mathrm{MHz})$ spectrometer with tetramethylsilane as an internal standard. Infrared (IR) spectra were recorded on a Shimadzu IR 435 and FTIR-5000 (Japan Spectroscopic Co., Ltd.). Mass spectra (MS) were measured with a Hitachi M-80B Mass Spectra. Optical rotation was taken with a DIP-360 Digital Polarimeter (Japan Spectroscopic Co., Ltd.) with a Thermostat Model RCS 6-D (Messengeraete-Werk Lauda, West Germany). X-Ray crystallography was conducted with a Rigaku AFC-5 Diffractometer.

7-Ethylcamptothecin (2) To a suspension of $1(1.00 \mathrm{~g}, 2.9 \mathrm{mmol})$ in water $(100 \mathrm{ml})$ containing $\mathrm{FeSO}_{4} \cdot 7 \mathrm{H}_{2} \mathrm{O}(300 \mathrm{mg}, 1.1 \mathrm{mmol})$ and propionaldehyde $(2 \mathrm{ml})$, conc. $\mathrm{H}_{2} \mathrm{SO}_{4}(11 \mathrm{ml})$ was dropwise added in an ice bath. To the mixture $30 \% \mathrm{H}_{2} \mathrm{O}_{2}(720 \mathrm{mg}, 6.4 \mathrm{mmol})$ was added with stirring. The stirring was continued for $3 \mathrm{~h}$ at room temperature. The mixture was diluted with $\mathrm{H}_{2} \mathrm{O}$ and the suspension was extracted with $\mathrm{CHCl}_{3}(100 \mathrm{ml} \times 3)$. The extracts were evaporated and the residue was 
passed through silica gel column chromatography with $2 \% \mathrm{MeOH}-\mathrm{CHCl}_{3}$. 2: $0.84 \mathrm{~g}, 77 \%$ yield as pale yellow needles, mp $258-261^{\circ} \mathrm{C}$ [EtOH]. IR (KBr) v: $1750,1650,1595 \mathrm{~cm}^{-1} .{ }^{1} \mathrm{H}-\mathrm{NMR}\left(\mathrm{CDCl}_{3}-\mathrm{DMSO}-d_{6}\right) \delta: 0.97$ $(3 \mathrm{H}, \mathrm{t}, J=7 \mathrm{~Hz}), 1.39(3 \mathrm{H}, \mathrm{t}, J=7 \mathrm{~Hz}), 1.91(2 \mathrm{H}, \mathrm{q}, J=7 \mathrm{~Hz}), 3.21(2 \mathrm{H}$ q, $J=7 \mathrm{~Hz}$ ), 521 (2H, s), 5.24, 5.57 (two $1 \mathrm{H}$ 's, d, $J=16 \mathrm{~Hz}), 7.49(1 \mathrm{H}, \mathrm{s}$ ) 7.44-8.21 (4H, m). MS $m / z: 376.1399\left[\mathrm{M}^{+}\right]$. Anal. Calod for $\mathrm{C}_{22} \mathrm{H}_{20} \mathrm{~N}_{2} \mathrm{O}_{4}: \mathrm{C}, 70.20 ; \mathrm{H}, 5.36 ; \mathrm{N}, 7.44$. Found: $\mathrm{C}, 70.37 ; \mathrm{H}, 5.35 ; \mathrm{N}, 7.39$.

7-Ethylcamptothecin 1-Oxide (3) A solution of $2(3.00 \mathrm{~g}, 8.0 \mathrm{mmol})$ and $30 \% \mathrm{H}_{2} \mathrm{O}_{2}(50 \mathrm{ml})$ in acetic acid $(800 \mathrm{ml})$ was heated at $70-80^{\circ} \mathrm{C}$ for $3.5 \mathrm{~h}$. The mixture was condensed to about one third at $45-55^{\circ} \mathrm{C}$ and the residue was poured into ice-water (31). The precipitated material in the solution was collected by suction. The filtered material was purified by recrystallization. $3: 2.4 \mathrm{~g}, 78 \%$ yield as yellow-orange needles, $\mathrm{mp} 255^{\circ} \mathrm{C}$ $\left[\mathrm{CHCl}_{3}-n-\mathrm{C}_{6} \mathrm{H}_{14}\right] .{ }^{1} \mathrm{H}-\mathrm{NMR}\left(\mathrm{DMSO}-d_{6}\right) \delta: 0.87(3 \mathrm{H}, \mathrm{t}, J=7 \mathrm{~Hz}), 1.28$ $(3 \mathrm{H}, \mathrm{t}, J=7 \mathrm{~Hz}), 1.84(2 \mathrm{H}, \mathrm{q}, J=7 \mathrm{~Hz}), 3.10(2 \mathrm{H}, \mathrm{q}, J=7 \mathrm{~Hz}), 5.26(2 \mathrm{H}$, s), $5.36(2 \mathrm{H}, \mathrm{s}), 6.24(1 \mathrm{H}, \mathrm{s}), 7.80(3 \mathrm{H}, \mathrm{m}), 8.19(1 \mathrm{H}, \mathrm{s}), 8.35(1 \mathrm{H}, \mathrm{m})$. MS $m / z: 392\left[\mathrm{M}^{+}\right]$for $\mathrm{C}_{22} \mathrm{H}_{20} \mathrm{~N}_{2} \mathrm{O}_{5}=392$.

7-Ethyl-10-hydroxycamptothecin (4) A solution of $3(1.00 \mathrm{~g}, 2.6 \mathrm{mmol})$ and $1 \mathrm{~N} \mathrm{H}_{2} \mathrm{SO}_{4}(2.6 \mathrm{ml})$ in dioxane $(11)$ was degassed by bubbling $\mathrm{N}_{2}$ for $20 \mathrm{~min}$. The mixture was irradiated by a high pressure $\mathrm{Hg}$ lamp $(450 \mathrm{~W}$, Usio UM-452) with a Pyrex filter for $30 \mathrm{~min}$ under stirring. The reaction mixture was evaporated to dryness and the residue was dissolved in $10 \%$ $\mathrm{MeOH}-\mathrm{CHCl}_{3}(50 \mathrm{ml})$. The solution was washed with water $(500 \mathrm{ml})$ and the insoluble material of both phases was collected on a Celite pad by suction and the Celite pad was eluted with $10 \% \mathrm{MeOH}-\mathrm{CHCl}_{3}(200 \mathrm{ml} \times 3)$. The eluents were condensed and the residue was washed with $\mathrm{MeOH}$ and then recrystallized. $4: 0.5 \mathrm{~g}, 49 \%$ yield as pale yellow needles, mp $216^{\circ} \mathrm{C}$ [EtOH]. IR (KBr) v: 3600, 3400, 3220, 2970, 1760, 1650, 1590, 1570, $1510 \mathrm{~cm}^{-1} .{ }^{1} \mathrm{H}-\mathrm{NMR}\left(\mathrm{CDCl}_{3}\right) \delta: 0.98(3 \mathrm{H}, \mathrm{t}, J=7 \mathrm{~Hz}), 1.38(3 \mathrm{H}, \mathrm{t}$, $J=7 \mathrm{~Hz}), 1.90(2 \mathrm{H}, \mathrm{q}, J=7 \mathrm{~Hz}), 3.08(2 \mathrm{H}, \mathrm{q}, J=7 \mathrm{~Hz}), 5.17(2 \mathrm{H}, \mathrm{s}), 5.23$, 5.54 (two 1H's d, $J=16 \mathrm{~Hz}), 7.34-7.39(3 \mathrm{H}, \mathrm{m}), 7.92(1 \mathrm{H}, \mathrm{d}, J=9 \mathrm{~Hz}$ ). MS m/z: $392\left[\mathrm{M}^{+}\right]$. Anal. Calcd for $\mathrm{C}_{22} \mathrm{H}_{20} \mathrm{~N}_{2} \mathrm{O}_{5} \cdot \mathrm{H}_{2} \mathrm{O}: \mathrm{C} ; 64.38, \mathrm{H} ; 5.40$, $\mathrm{N} ; 6.83$. Found: $\mathrm{C} ; 64.24, \mathrm{H} ; 5.31, \mathrm{~N} ; 6.68$.

General Procedure for the Preparation of Carbamate Linked Derivatives (6) by the Reaction of 4 with Chlorocarbonyldiamines To a benzene solution of diamine $(60 \mathrm{~g})$, phosgen dimer $(50 \mathrm{ml})$ in benzene was dropwise added with stirring under $\mathrm{N}_{2}$ atmosphere below $10^{\circ} \mathrm{C}$. The stirring was continued for an additional hour at an ambient temperature. The precipitates were collected on a filter paper by suction. The collected material was dissolved in $\mathrm{CH}_{2} \mathrm{Cl}_{2}$ and the solution was washed with $7 \%$ $\mathrm{NaHCO}_{3}$, dried over $\mathrm{MgSO}_{4}$, filtered, and then evaporated to dryness in vacuo. The residue was passed through a silica gel column with $\mathrm{CH}_{2} \mathrm{Cl}_{2}$-acetone $(500: 1)$.

The solution of compound 4 and chlorocarbonyl diamine (1.1 eq) in pyridine was stirred for $15 \mathrm{~h}$ at an ambient temperature. The mixture was evaporated to dryness in vacuo. The residue was dissolved in $\mathrm{CH}_{2} \mathrm{Cl}_{2}$ and the solution was shaken with $7 \% \mathrm{NaHCO}_{3}$, the organic layer was dried over $\mathrm{MgSO}_{4}$, filtered, and condensed in vacuo. The residue was purified through a silica gel column with $\mathrm{MeOH}-\mathrm{CHCl}_{3}(1: 20)$.

Compounds $6-09,10,11,23-27$, and 28 were obtained by this method.

General Procedure for the Preparation of 6 by the Reaction of 7-Ethyl-10-chlorocarbonyloxycamptothecin (5) with Diamines: $4(5.00 \mathrm{~g}, 12.8$ $\mathrm{mmol})$ was dissolved in dioxane $(10 \mathrm{l})$ containing triethylamine $(50 \mathrm{ml})$, and phosgen [generated from phosgen dimer $(3.75 \mathrm{ml})$ on active charcoal] was passed through the mixture with stirring at room temperature. The stirring was continued for an additional hour. The solution was filtered by suction and the filtrate was condensed to dryness in vacuo. The residue was triturated with acetone and collected on a filter paper to afford 5 $(5.2 \mathrm{~g}, 90.0 \%$ yield) as colorless powder.

$5(3.0 \mathrm{~g})$ was dissolved in a mixture of $\mathrm{CH}_{2} \mathrm{Cl}_{2}-\mathrm{MeOH}(500 \mathrm{ml}-150 \mathrm{ml})$ containing pyridine $(15 \mathrm{ml})$, and then diamine $(2.0 \mathrm{eq})$ in $\mathrm{CH}_{2} \mathrm{Cl}_{2}$ was added dropwise to the mixture with stirring. The mixture was stirred for $15 \mathrm{~h}$ at room temperature and was condensed to dryness in vacuo. The residue was dissolved in $\mathrm{CH}_{2} \mathrm{Cl}_{2}$ and the solution was washed with $7 \%$ $\mathrm{NaHCO}_{3}$ and then the organic layer was dried over $\mathrm{MgSO}_{4}$, filtered, and evaporated in vacuo. The residue was purified through silica gel column chromatography with $4 \% \mathrm{MeOH}-\mathrm{CH}_{2} \mathrm{Cl}_{2}$

Carbamate linked derivatives (6) other than described above were obtained by this method.

6-01: $25.5 \%$ yield as pale yellow needles, mp $228-230{ }^{\circ} \mathrm{C}\left[n-\mathrm{C}_{6} \mathrm{H}_{14}-\right.$ $\mathrm{CHCl}_{3}$ ]. IR (KBr) v: 3430, 2960, 1745, 1718, 1660, 1590, $1413 \mathrm{~cm}^{-1}$. ${ }^{1} \mathrm{H}-\mathrm{NMR}$ (DMSO- $\left.d_{6}\right) \delta: 0.90(3 \mathrm{H}, \mathrm{t}, J=7 \mathrm{~Hz}), 1.32(3 \mathrm{H}, \mathrm{t}, J=7 \mathrm{~Hz}), 1.97$ $(2 \mathrm{H}, \mathrm{q}, J=7 \mathrm{~Hz}), 3.04-3.65(10 \mathrm{H}, \mathrm{m}), 5.32(2 \mathrm{H}, \mathrm{s}), 5.44(2 \mathrm{H}, \mathrm{s}), 6.50(1 \mathrm{H}$, s), $7.34(1 \mathrm{H}, \mathrm{s}), 7.66(1 \mathrm{H}, \mathrm{dd}, J=2,8 \mathrm{~Hz}), 7.97(1 \mathrm{H}, \mathrm{d}, J=2 \mathrm{~Hz}), 8.16(1 \mathrm{H}$, d, $J=8 \mathrm{~Hz}$ ). Anal. Calcd for $\mathrm{C}_{27} \mathrm{H}_{28} \mathrm{~N}_{4} \mathrm{O}_{6} \cdot \mathrm{H}_{2} \mathrm{O}: \mathrm{C}, 62.05 ; \mathrm{H}, 5.79 ; \mathrm{N}$,
10.72. Found: C, $62.05 ; \mathrm{H}, 5.42 ; \mathrm{N}, 10.96$.

6-02: $54.2 \%$ yield as pale yellow needles, mp $236-239^{\circ} \mathrm{C}\left[n-\mathrm{C}_{6} \mathrm{H}_{14}\right.$ $\left.\mathrm{CHCl}_{3}\right]$. IR (KBr) v: $3430,2970,1743,1715,1655,1598,1459 \mathrm{~cm}^{-1}$ ${ }^{1} \mathrm{H}-\mathrm{NMR}\left(\mathrm{DMSO}-d_{6}\right) \delta: 0.88(3 \mathrm{H}, \mathrm{t}, J=7 \mathrm{~Hz}), 1.29(3 \mathrm{H}, \mathrm{t}, J=7 \mathrm{~Hz}), 1.87$ $(2 \mathrm{H}, \mathrm{q}, J=7 \mathrm{~Hz}), 2.25(3 \mathrm{H}, \mathrm{s}), 3.18(2 \mathrm{H}, \mathrm{q}, J=7 \mathrm{~Hz}), 3,49-3.64(8 \mathrm{H}, \mathrm{m})$, $5.31(2 \mathrm{H}, \mathrm{s}), 5.43(2 \mathrm{H}, \mathrm{s}), 6.50(1 \mathrm{H}, \mathrm{s}), 7.31(1 \mathrm{H}, \mathrm{s}), 7.64(1 \mathrm{H}, \mathrm{dd}, J=2$, $9 \mathrm{~Hz}), 7.97(1 \mathrm{H}, \mathrm{d}, J=2 \mathrm{~Hz}), 8.15(1 \mathrm{H}, \mathrm{d}, J=9 \mathrm{~Hz}) . \mathrm{MS} m / z 518\left[\mathrm{M}^{+}\right]$. Anal. Calcd for $\mathrm{C}_{30} \mathrm{H}_{34} \mathrm{~N}_{4} \mathrm{O}_{7} \cdot 1 / 2 \mathrm{H}_{2} \mathrm{O}: \mathrm{C}, 63.75 ; \mathrm{H}, 5.92 ; \mathrm{N}, 10.62$. Found: C, $63.87 ; \mathrm{H}, 5.74 ; \mathrm{N}, 10.71$.

6-03: $75.3 \%$ yield as pale yellow needles, $\mathrm{mp} 200-203{ }^{\circ} \mathrm{C}\left[\mathrm{n}-\mathrm{C}_{6} \mathrm{H}_{14}-\right.$ $\mathrm{CHCl}_{3}$ ]. IR (KBr) v: 3430, 2960, 1742, 1720, 1655, 1597, $1412 \mathrm{~cm}^{-1}$ ${ }^{1} \mathrm{H}-\mathrm{NMR}$ (DMSO- $\left.d_{6}\right) \delta: 0.90(3 \mathrm{H}, \mathrm{t}, J=7 \mathrm{~Hz}), 1.06(3 \mathrm{H}, \mathrm{t}, J=7 \mathrm{~Hz}), 1.32$ $(3 \mathrm{H}, \mathrm{t}, J=7 \mathrm{~Hz}), 1.90(2 \mathrm{H}, \mathrm{q}, J=7 \mathrm{~Hz}), 2.42(2 \mathrm{H}, \mathrm{q}, J=7 \mathrm{~Hz}), 2.18-3.17$ $(10 \mathrm{H}, \mathrm{m}), 5.32(2 \mathrm{H}, \mathrm{s}), 5.44(2 \mathrm{H}, \mathrm{s}), 6.48(1 \mathrm{H}, \mathrm{s}), 7.35(1 \mathrm{H}, \mathrm{s}), 7.66(1 \mathrm{H}$, dd, $J=2,8 \mathrm{~Hz}$ ), 7.99 (1H, d, $J=2 \mathrm{~Hz}), 8.18(1 \mathrm{H}, \mathrm{d}, J=8 \mathrm{~Hz}) . \mathrm{MS} \mathrm{m} / \mathrm{z}$ : $532\left[\mathrm{M}^{+}\right]$for $\mathrm{C}_{29} \mathrm{H}_{32} \mathrm{~N}_{4} \mathrm{O}_{6}=532$.

6-04: $34.7 \%$ yield as pale yellow needles, $\mathrm{mp} 210-213{ }^{\circ} \mathrm{C}\left[n-\mathrm{C}_{6} \mathrm{H}_{14}\right.$ $\mathrm{CHCl}_{3}$ ]. IR (KBr) v: 3440, 2960,1750,1720,1655, 1598, $1412 \mathrm{~cm}^{-1}$. ${ }^{1} \mathrm{H}-\mathrm{NMR}\left(\mathrm{CDCl}_{3}\right) \delta: 0.93(3 \mathrm{H}, \mathrm{t}, J=7 \mathrm{~Hz}), 1.02(3 \mathrm{H}, \mathrm{t}, J=7 \mathrm{~Hz}), 1.38$ $(3 \mathrm{H}, \mathrm{t}, J=7 \mathrm{~Hz}), 1.50-1.60(2 \mathrm{H}, \mathrm{m}), 1.87(2 \mathrm{H}, \mathrm{q}, J=7 \mathrm{~Hz}), 2.51(2 \mathrm{H}, \mathrm{q}$, $J=7 \mathrm{~Hz}), 3.11(2 \mathrm{H}, \mathrm{q}, J=7 \mathrm{~Hz}), 3.50-3.90(8 \mathrm{H}, \mathrm{m}), 5.16(2 \mathrm{H}, \mathrm{s}), 5.23$ $(1 \mathrm{H}, \mathrm{d}, J=16 \mathrm{~Hz}), 5.47(1 \mathrm{H}, \mathrm{d}, J=16 \mathrm{~Hz}), 7.45$ (1H, dd, $J=2$, $8 \mathrm{~Hz}), 7.50(1 \mathrm{H}, \mathrm{s}), 7.70(1 \mathrm{H}, \mathrm{d}, J=2 \mathrm{~Hz}), 8.07(1 \mathrm{H}, \mathrm{d}, J=8 \mathrm{~Hz}) . \mathrm{MS} m / z$ : $546\left[\mathrm{M}^{+}\right]$for $\mathrm{C}_{30} \mathrm{H}_{34} \mathrm{~N}_{4} \mathrm{O}_{6}=546$.

6-05: $29 \%$ yield as pale yellow needles, mp $226-230.5^{\circ} \mathrm{C}\left[n-\mathrm{C}_{6} \mathrm{H}_{14}\right.$ $\mathrm{CHCl}_{3}$ ]. IR (KBr)v: 3400, 2950, 1750, 1715, 1650,1600, $1450 \mathrm{~cm}^{-1}$ ${ }^{1} \mathrm{H}-\mathrm{NMR}\left(\mathrm{CDCl}_{3}\right) \delta: 1.04(3 \mathrm{H}, \mathrm{t}, J=7 \mathrm{~Hz}), 1.41(3 \mathrm{H}, \mathrm{t}, J=7 \mathrm{~Hz})$, $1.40-2.20(9 \mathrm{H}, \mathrm{br}), 1.80-2.20(2 \mathrm{H}, \mathrm{m}), 2.50-2.70(4 \mathrm{H}, \mathrm{br} \mathrm{m}), 3.16(2 \mathrm{H}$, $\mathrm{q}, J=7 \mathrm{~Hz}), 3.60-3.90(4 \mathrm{H}, \mathrm{brm}), 5.26(2 \mathrm{H}, \mathrm{s}), 5.31(1 \mathrm{H}, \mathrm{d}, J=16 \mathrm{~Hz})$, $5.75(1 \mathrm{H}, \mathrm{d}, J=16 \mathrm{~Hz}), 7.60(1 \mathrm{H}, \mathrm{dd}, J=2,8 \mathrm{~Hz}), 7.64(1 \mathrm{H}, \mathrm{s}), 7.85(1 \mathrm{H}$, d, $J=2 \mathrm{~Hz}), 8.22$ (1H, d, $J=8 \mathrm{~Hz})$.

6-06: $81.8 \%$ yield as pale yellow needles, mp $160-162{ }^{\circ} \mathrm{C}\left[n-\mathrm{C}_{6} \mathrm{H}_{14}-\right.$ $\mathrm{CHCl}_{3}$ ]. IR (KBr) $v: 3440,2940,1745,1720,1655,1600,1415 \mathrm{~cm}^{-1}$ ${ }^{1} \mathrm{H}-\mathrm{NMR}\left(\mathrm{DMSO}-d_{6}\right) \delta: 0.89(3 \mathrm{H}, \mathrm{t}, J=7 \mathrm{~Hz}), 1.29(3 \mathrm{H}, \mathrm{t}, J=7 \mathrm{H}), 1.87$ $(2 \mathrm{H}, \mathrm{q}, J=7 \mathrm{~Hz}), 3.19(2 \mathrm{H}, \mathrm{q}, J=7 \mathrm{~Hz}), 3.56(2 \mathrm{H}, \mathrm{s}), 3.50-3.70(8 \mathrm{H}, \mathrm{m})$, $5.32(2 \mathrm{H}, \mathrm{s}), 5.43(2 \mathrm{H}, \mathrm{s}), 6.50(1 \mathrm{H}, \mathrm{s}), 7.32(1 \mathrm{H}, \mathrm{s}), 7.34(5 \mathrm{H}, \mathrm{br} \mathrm{s}), 7.45$ $(1 \mathrm{H}, \mathrm{dd}, J=2,8 \mathrm{~Hz}), 7.97(1 \mathrm{H}, \mathrm{d}, J=2 \mathrm{~Hz}), 8.16(1 \mathrm{H}, \mathrm{d}, J=8 \mathrm{~Hz})$. Anal. Calcd for $\mathrm{C}_{34} \mathrm{H}_{34} \mathrm{~N}_{4} \mathrm{O}_{6} \cdot 1 / 2 \mathrm{H}_{2} \mathrm{O}: \mathrm{C}, 66.65 ; \mathrm{H}, 5.92 ; \mathrm{N}, 9.14$.

6-07: $48.5 \%$ yield as pale yellow powder, $\mathrm{mp} 228-230^{\circ} \mathrm{C}\left[n-\mathrm{C}_{6} \mathrm{H}_{14}\right.$ $\mathrm{CHCl}_{3}$ ]. IR (KBr) v: 3300, 2940, 1745, 1709, 1655, 1592, $1412 \mathrm{~cm}^{-1}$. ${ }^{1} \mathrm{H}-\mathrm{NMR}\left(\mathrm{DMSO}-d_{6}\right) \delta: 0.89(3 \mathrm{H}, \mathrm{t}, J=7 \mathrm{~Hz}), 1.30(3 \mathrm{H}, \mathrm{t}, J=7 \mathrm{~Hz}), 1.63$ $(2 \mathrm{H}, \mathrm{m}), 1.88(2 \mathrm{H}, \mathrm{q}, J=7 \mathrm{~Hz}), 3.20-3.65(14 \mathrm{H}, \mathrm{m}), 5.32(2 \mathrm{H}, \mathrm{s}), 5.43$ $(2 \mathrm{H}, \mathrm{s}), 6.51(1 \mathrm{H}, \mathrm{s}), 7.32(1 \mathrm{H}, \mathrm{s}), 7.65(1 \mathrm{H}, \mathrm{dd}, J=2,8 \mathrm{~Hz}), 7.98(1 \mathrm{H}, \mathrm{d}$, $J=2 \mathrm{~Hz}), 8.17(1 \mathrm{H}, \mathrm{d}, J=8 \mathrm{~Hz})$.

6-08: $23 \%$ yield as pale yellow powder, mp $198-200{ }^{\circ} \mathrm{C}\left[n-\mathrm{C}_{6} \mathrm{H}_{14}-\right.$ $\mathrm{CHCl}_{3}$ ]. IR (KBr) v: $3390,2960,1745,1715,1655,1595,1455 \mathrm{~cm}^{-1}$. ${ }^{1} \mathrm{H}-\mathrm{NMR}\left(\mathrm{CDCl}_{3}\right) \delta: 1.04(3 \mathrm{H}, \mathrm{t}, J=7 \mathrm{~Hz}), 1.41(3 \mathrm{H}, \mathrm{t}, J=7 \mathrm{~Hz})$, $1.80-2.00(2 \mathrm{H}, \mathrm{m}), 2.64(4 \mathrm{H}, \mathrm{t}, J=4 \mathrm{~Hz}), 2.68(2 \mathrm{H}, \mathrm{t}, J=4 \mathrm{~Hz}), 3.16(2 \mathrm{H}$, $\mathrm{q}, J=7 \mathrm{~Hz}), 3.63(2 \mathrm{H}, \mathrm{t}, J=3 \mathrm{~Hz}), 3.70(2 \mathrm{H}, \mathrm{t}, J=5.5 \mathrm{~Hz}), 3.73(6 \mathrm{H}, \mathrm{m})$, $5.25(2 \mathrm{H}, \mathrm{s}), 5.29(1 \mathrm{H}, \mathrm{d}, J=16 \mathrm{~Hz}), 5.74(2 \mathrm{H}, \mathrm{d}, J=16 \mathrm{~Hz}), 7.58(1 \mathrm{H}$, dd, $J=2,8 \mathrm{~Hz}), 7.62(1 \mathrm{H}, \mathrm{s}), 7.85(1 \mathrm{H}, \mathrm{d}, J=2 \mathrm{~Hz}), 8.21(1 \mathrm{H}, \mathrm{d}, J=8 \mathrm{~Hz})$.

6-09: $75.9 \%$ yield as pale yellow needles, mp $237-240^{\circ} \mathrm{C}\left[\mathrm{n}-\mathrm{C}_{6} \mathrm{H}_{14}\right.$ $\left.\mathrm{CHCl}_{3}\right]$. IR (KBr) v: $3420,3340,2960,1750,1720,1655,1595 \mathrm{~cm}^{-1}$. ${ }^{1} \mathrm{H}-\mathrm{NMR}$ (DMSO- $\left.d_{6}\right) \delta: 0.89(3 \mathrm{H}, \mathrm{t}, J=7 \mathrm{~Hz}), 1.09(6 \mathrm{H}, \mathrm{d}, J=6 \mathrm{~Hz}), 1.30$ $(3 \mathrm{H}, \mathrm{t}, J=7 \mathrm{~Hz}), 1.88(2 \mathrm{H}, \mathrm{q}, J=7 \mathrm{~Hz}), 2.60(4 \mathrm{H}, \mathrm{br} \mathrm{s}), 3.40-3.70(4 \mathrm{H}$, $\mathrm{m}), 3.70-4.00(1 \mathrm{H}, \mathrm{m}), 5.32(2 \mathrm{H}, \mathrm{s}), 5.43(2 \mathrm{H}, \mathrm{s}), 6.50(1 \mathrm{H}, \mathrm{s}), 7.32(1 \mathrm{H}$, s), $7.65(1 \mathrm{H}, \mathrm{dd}, J=2,8 \mathrm{~Hz}), 7.98(1 \mathrm{H}, \mathrm{d}, J=2 \mathrm{~Hz}), 8.16(1 \mathrm{H}, \mathrm{d}, J=8 \mathrm{~Hz})$. Anal. Calcd for $\mathrm{C}_{32} \mathrm{H}_{37} \mathrm{~N}_{5} \mathrm{O}_{7} \cdot \mathrm{H}_{2} \mathrm{O}: \mathrm{C}, 61.88 ; \mathrm{H}, 6.33 ; \mathrm{N}, 11.28$. Found: C, $61.89 ; \mathrm{H}, 6.33 ; \mathrm{N}, 11.28$.

6-10: $78.5 \%$ yield as pale yellow needles, $\mathrm{mp} 165.5-166.5^{\circ} \mathrm{C}$ [EtOH]. IR (KBr) $v: 3395,2955,1745,1715,1655,1615,1450 \mathrm{~cm}^{-1}{ }^{1}{ }^{2} \mathrm{H}-\mathrm{NMR}$ $\left(\mathrm{CDCl}_{3}\right) \delta: 1.03(3 \mathrm{H}, \mathrm{t}, J=7 \mathrm{~Hz}), 1.40(3 \mathrm{H}, \mathrm{t}, J=7 \mathrm{~Hz}), 1.80-1.95(2 \mathrm{H}$, $\mathrm{m}), 1.95-2.05(4 \mathrm{H}, \mathrm{m}), 2.65-2.80(4 \mathrm{H}, \mathrm{m}), 3.16(2 \mathrm{H}, \mathrm{q}, J=7 \mathrm{~Hz}), 3.23$ $(2 \mathrm{H}, \mathrm{s}), 3.50(4 \mathrm{H}, \mathrm{dd}, J=7,14 \mathrm{~Hz}), 3.65-3.85(4 \mathrm{H}, \mathrm{m}), 5.25(2 \mathrm{H}, \mathrm{s}), 5.30$ $(1 \mathrm{H}, \mathrm{d}, J=16 \mathrm{~Hz}), 5.74(1 \mathrm{H}, \mathrm{d}, J=16 \mathrm{~Hz}), 7.58(1 \mathrm{H}, \mathrm{dd}, J=2,9 \mathrm{~Hz}), 7.65$ (1H, s), $7.84(1 \mathrm{H}, \mathrm{d}, J=2 \mathrm{~Hz}), 8.21(1 \mathrm{H}, \mathrm{d}, J=9 \mathrm{~Hz})$. Anal. Calcd for $\mathrm{C}_{33} \mathrm{H}_{37} \mathrm{~N}_{5} \mathrm{O}_{8} \cdot \mathrm{H}_{2} \mathrm{O}: \mathrm{C}, 62.55 ; \mathrm{H}, 6.20 ; \mathrm{N}, 11.05$. Found: $\mathrm{C}, 62.45 ; \mathrm{H}, 6.05$; $\mathrm{N}, 11.12$.

6-11: $62.7 \%$ yield and pale yellow needles, $\mathrm{mp} 205.5-208^{\circ} \mathrm{C}$ [EtOH]. IR (KBr) $v: 3400,2960,1745,1710,1650,1595,1455 \mathrm{~cm}^{-1} .{ }^{1} \mathrm{H}-\mathrm{NMR}$ $\left(\mathrm{CDCl}_{3}\right) \delta: 1.04(3 \mathrm{H}, \mathrm{t}, J=7 \mathrm{~Hz}), 1.40(3 \mathrm{H}, \mathrm{t}, J=7 \mathrm{~Hz}), 1.61(2 \mathrm{H}, \mathrm{m})$, $1.80-2.00(2 \mathrm{H}, \mathrm{m}), 1.90-2.05(2 \mathrm{H}, \mathrm{m}), 2.46(1 \mathrm{H}, \mathrm{m}), 2.61(4 \mathrm{H}, \mathrm{m}), 2.96$ (1H, br m), $3.13(1 \mathrm{H}, \mathrm{m}), 3.16(2 \mathrm{H}, \mathrm{q}, J=7 \mathrm{~Hz}), 3.76(4 \mathrm{H}, \mathrm{t}, J=3.5 \mathrm{~Hz})$, $3.85(1 \mathrm{H}, \mathrm{brs}), 4.23(1 \mathrm{H}, \mathrm{d}, J=13 \mathrm{~Hz}), 4.42(1 \mathrm{H}, \mathrm{d}, J=13 \mathrm{~Hz}), 5.26(2 \mathrm{H}$, s), $5.31(1 \mathrm{H}, \mathrm{d}, J=16 \mathrm{~Hz}), 5.75(1 \mathrm{H}, \mathrm{d}, J=16 \mathrm{~Hz}), 7.58(1 \mathrm{H}, \mathrm{dd}, J=2$, 
$9 \mathrm{~Hz}), 7.65(1 \mathrm{H}, \mathrm{s}), 7.83(1 \mathrm{H}, \mathrm{d}, J=2 \mathrm{~Hz}), 8.22(1 \mathrm{H}, \mathrm{d}, J=9 \mathrm{~Hz})$. Anal. Calcd for $\mathrm{C}_{33} \mathrm{H}_{37} \mathrm{~N}_{5} \mathrm{O}_{8} \cdot 1 / 2 \mathrm{H}_{2} \mathrm{O}: \mathrm{C}, 61.86 ; \mathrm{H}, 5.98 ; \mathrm{N}, 10.93$. Found: $\mathrm{C}$, 62.06; $\mathrm{H}, 5.78 ; \mathrm{N}, 10.94$

6-12: $38.0 \%$ yield as pale yellow needles, mp $202-204^{\circ} \mathrm{C}\left[n-\mathrm{C}_{6} \mathrm{H}_{14}\right.$ $\left.\mathrm{CHCl}_{3}\right]$. IR (KBr) v: $3400,2960,1745,1715,1655,1600,1510$, $1450 \mathrm{~cm}^{-1} .{ }^{1} \mathrm{H}-\mathrm{NMR}\left(\mathrm{CDCl}_{3}\right) \delta: 1.04(3 \mathrm{H}, \mathrm{t}, J=7 \mathrm{~Hz}), 1.42(3 \mathrm{H}, \mathrm{t}$ $J=7 \mathrm{~Hz}), 1.80-2.00(2 \mathrm{H}, \mathrm{m}), 3.10-3.30(4 \mathrm{H}, \mathrm{m}), 3.17(2 \mathrm{H}, \mathrm{q}, J=7 \mathrm{~Hz})$, $3.80-4.00(4 \mathrm{H}, \mathrm{m}), 5.27(2 \mathrm{H}, \mathrm{s}), 5.31(1 \mathrm{H}, \mathrm{d}, J=16 \mathrm{~Hz}), 5.75(1 \mathrm{H}, \mathrm{d}$ $J=16 \mathrm{~Hz}), 7.04-7.45(5 \mathrm{H}, \mathrm{br} \mathrm{s}), 7.62(1 \mathrm{H}, \mathrm{dd}, J=2,8 \mathrm{~Hz}), 7.65(1 \mathrm{H}, \mathrm{s})$ $7.91(\mathrm{lH}, \mathrm{d}, J=2 \mathrm{~Hz}), 8.21(1 \mathrm{H}, \mathrm{d}, J=8 \mathrm{~Hz})$. MS $m / z: 580\left[\mathrm{M}^{+}\right]$for $\mathrm{C}_{33} \mathrm{H}_{32} \mathrm{~N}_{4} \mathrm{O}_{6}=580$.

6-13: $36 \%$ yield as pale yellow powder, mp $241-242{ }^{\circ} \mathrm{C}\left[n-\mathrm{C}_{6} \mathrm{H}_{14}\right.$ $\left.\mathrm{CHCl}_{3}\right]$. IR (KBr) v: 3400, 2960, 1743, 1715, 1655, 1600, 1510 $1450 \mathrm{~cm}^{-1} .{ }^{1} \mathrm{H}-\mathrm{NMR}\left(\mathrm{CDCl}_{3}\right) \delta: 1.04(3 \mathrm{H}, \mathrm{t}, J=7 \mathrm{~Hz}), 1.42(3 \mathrm{H}, \mathrm{t}$ $J=7 \mathrm{~Hz}), 1.80-2.00(2 \mathrm{H}, \mathrm{m}), 3.10-3.30(4 \mathrm{H}, \mathrm{m}), 3.16(2 \mathrm{H}, \mathrm{q}, J=7 \mathrm{~Hz})$ $3.80-4.00(4 \mathrm{H}, \mathrm{m}), 5.27(2 \mathrm{H}, \mathrm{s}), 5.31(1 \mathrm{H}, \mathrm{d}, J=16 \mathrm{~Hz}), 5.75(1 \mathrm{H}, \mathrm{d}$ $J=16 \mathrm{~Hz}$ ), $7.04-7.42(4 \mathrm{H}, \mathrm{m}), 7.62(1 \mathrm{H}, \mathrm{dd}, J=2,8 \mathrm{~Hz}), 7.65(1 \mathrm{H}, \mathrm{s}), 7.88$ $(1 \mathrm{H}, \mathrm{d}, J=2 \mathrm{~Hz}), 8.24(1 \mathrm{H}, \mathrm{d}, J=8 \mathrm{~Hz})$.

6-14: $33 \%$ yield as pale yellow powder, mp $159-163{ }^{\circ} \mathrm{C}\left[n-\mathrm{C}_{6} \mathrm{H}_{14}\right.$ $\mathrm{CHCl}_{3}$ ]. IR (KBr) $v: 3400,2960,1750,1720,1655,1590,1455 \mathrm{~cm}^{-1}$ ${ }^{1} \mathrm{H}$-NMR $\left(\mathrm{CDCl}_{3}\right) \delta: 1.41(3 \mathrm{H}, \mathrm{t}, J=7 \mathrm{~Hz}), 1.80-2.00(2 \mathrm{H}, \mathrm{m}), 3.16$ (2H, q, $J=7 \mathrm{~Hz}), 3.30(4 \mathrm{H}, \mathrm{m}), 3.70-3.90(4 \mathrm{H}, \mathrm{m}), 5.24(2 \mathrm{H}, \mathrm{s}), 5.29(1 \mathrm{H}$ $\mathrm{d}, J=16 \mathrm{~Hz}), 5.72(1 \mathrm{H}, \mathrm{d}, J=16 \mathrm{~Hz}), 6.83-7.20(4 \mathrm{H}, \mathrm{m}), 7.59(1 \mathrm{H}, \mathrm{dd}$ $J=2,8 \mathrm{~Hz}), 7.62(1 \mathrm{H}, \mathrm{s}), 7.87(1 \mathrm{H}, \mathrm{d}, J=2 \mathrm{~Hz}), 8.22(1 \mathrm{H}, \mathrm{d}, J=8 \mathrm{~Hz})$.

6-15: $31 \%$ yield as pale yellow powder, $\mathrm{mp} 179-180.5^{\circ} \mathrm{C}\left[n-\mathrm{C}_{6} \mathrm{H}_{14}\right.$ $\left.\mathrm{CHCl}_{3}\right]$. IR (KBr) v: $3410,2970,1740,1715,1660,1595,1490 \mathrm{~cm}^{-1}$ ${ }^{1} \mathrm{H}-\mathrm{NMR}\left(\mathrm{CDCl}_{3}\right) \delta: 1.04(3 \mathrm{H}, \mathrm{t}, J=7 \mathrm{~Hz}), 1.41(3 \mathrm{H}, \mathrm{t}, J=7 \mathrm{~Hz})$ $1.80-2.00(2 \mathrm{H}, \mathrm{m}), 3.17(2 \mathrm{H}, \mathrm{q}, J=7 \mathrm{~Hz}), 3.20-3.30(4 \mathrm{H}, \mathrm{m})$ $3.70-4.00(4 \mathrm{H}, \mathrm{m}), 5.26(1 \mathrm{H}, \mathrm{s}), 5.31(1 \mathrm{H}, \mathrm{d}, J=16 \mathrm{~Hz}), 5.75(1 \mathrm{H}, \mathrm{d}$ $J=16 \mathrm{~Hz}), 6.90(2 \mathrm{H}, \mathrm{d}, J=9 \mathrm{~Hz}), 7.26(2 \mathrm{H}, \mathrm{d}, J=9 \mathrm{~Hz}), 7.61(1 \mathrm{H}, \mathrm{dd}$, $J=2,8 \mathrm{~Hz}), 7.87(1 \mathrm{H}, \mathrm{d}, J=2 \mathrm{~Hz}), 8.24(1 \mathrm{H}, \mathrm{d}, J=8 \mathrm{~Hz})$.

6-16: $63.3 \%$ yield as pale yellow needles, $\mathrm{mp} 156-158^{\circ} \mathrm{C}\left[n-\mathrm{C}_{6} \mathrm{H}_{14}\right.$ $\mathrm{CHCl}_{3}$ ]. IR (KBr) v: 3440, 2970, 1745, 1720, 1658, 1600, 1515, $1415 \mathrm{~cm}^{-1}$ ${ }^{1} \mathrm{H}-\mathrm{NMR}\left(\mathrm{DMSO}-d_{6}\right) \delta: 0.89(3 \mathrm{H}, \mathrm{t}, J=7 \mathrm{~Hz}), 1.30(3 \mathrm{H}, \mathrm{t}, J=7 \mathrm{~Hz})$, $1.88(2 \mathrm{H}, \mathrm{q}, J=7 \mathrm{~Hz}), 3.14(6 \mathrm{H}, \mathrm{brs}), 5.26(1 \mathrm{H}, \mathrm{s}), 5.44(2 \mathrm{H}, \mathrm{s}), 6.50$ $(1 \mathrm{H}, \mathrm{s}), 6.91(4 \mathrm{H}, \mathrm{m}), 7.32(1 \mathrm{H}, \mathrm{s}), 7.69(1 \mathrm{H}, \mathrm{dd}, J=2,8 \mathrm{~Hz}), 8.01(1 \mathrm{H}, \mathrm{d}$ $J=2 \mathrm{~Hz}), 8.18(1 \mathrm{H}, \mathrm{d}, J=8 \mathrm{~Hz})$.

6-17: $38 \%$ yield as pale yellow needles, mp $230.5-232.5^{\circ} \mathrm{C}\left[n-\mathrm{C}_{6} \mathrm{H}_{14}\right.$ $\left.\mathrm{CHCl}_{3}\right]$. IR (KBr) v: 3400, 2960, 1745, 1720, 1655, 1585, 1540, $1490 \mathrm{~cm}^{-1}$ ${ }^{1} \mathrm{H}-\mathrm{NMR}\left(\mathrm{CDCl}_{3}\right) \delta: 1.03(3 \mathrm{H}, \mathrm{t}, J=7 \mathrm{~Hz}), 1.41(3 \mathrm{H}, \mathrm{t}, J=7 \mathrm{~Hz})$, $1.80-2.00(2 \mathrm{H}, \mathrm{m}), 3.17(2 \mathrm{H}, \mathrm{q}, J=7 \mathrm{~Hz}), 5.26(1 \mathrm{H}, \mathrm{s}), 5.31(1 \mathrm{H}, \mathrm{d}$, $J=16 \mathrm{~Hz}), 5.75(1 \mathrm{H}, \mathrm{d}, J=16 \mathrm{~Hz}), 6.58(1 \mathrm{H}, \mathrm{t}, J=5 \mathrm{~Hz}), 7.62(1 \mathrm{H}$, dd, $J=2,8 \mathrm{~Hz}), 7.65(1 \mathrm{H}, \mathrm{s}), 7.87(1 \mathrm{H}, \mathrm{d}, J=2 \mathrm{~Hz}), 8.23(1 \mathrm{H}, \mathrm{d}, J=8 \mathrm{~Hz})$, $8.37(2 \mathrm{H}, \mathrm{d}, J=5 \mathrm{~Hz})$. MS $m / z: 581\left[\mathrm{M}^{+}\right]$for $\mathrm{C}_{32} \mathrm{H}_{31} \mathrm{~N}_{5} \mathrm{O}_{6}=581$.

6-18: $34 \%$ yield as pale yellow needles, mp $229-230.5^{\circ} \mathrm{C}\left[n-\mathrm{C}_{6} \mathrm{H}_{14}\right.$ $\mathrm{CHCl}_{3}$ ]. IR (KBr) v: $3400,2960,1745,1720,1655,1590,1475 \mathrm{~cm}^{-1}$ ${ }^{1} \mathrm{H}-\mathrm{NMR}\left(\mathrm{CDCl}_{3}\right) \delta: 1.04(3 \mathrm{H}, \mathrm{t}, J=7 \mathrm{~Hz}), 1.41(3 \mathrm{H}, \mathrm{t}, J=7 \mathrm{~Hz})$, $1.80-2.00(2 \mathrm{H}, \mathrm{m}), 3.17(2 \mathrm{H}, \mathrm{q}, J=7 \mathrm{~Hz}), 3.60-4.00(8 \mathrm{H}, \mathrm{m})$, $5.26(1 \mathrm{H}, \mathrm{s}), 5.31(1 \mathrm{H}, \mathrm{d}, J=16 \mathrm{~Hz}), 5.75(1 \mathrm{H}, \mathrm{d}, J=16 \mathrm{~Hz}), 6.70-6.72$ $(2 \mathrm{H}, \mathrm{m}), 7.55-7.61(2 \mathrm{H}, \mathrm{m}), 7.61(1 \mathrm{H}, \mathrm{dd}, J=2,8 \mathrm{~Hz}), 7.65(1 \mathrm{H}, \mathrm{s}), 7.87$ $(1 \mathrm{H}, \mathrm{d}, J=2 \mathrm{~Hz}), 8.24(1 \mathrm{H}, \mathrm{d}, J=8 \mathrm{~Hz})$.

6-19: $36 \%$ yield as pale yellow powder, $\mathrm{mp} 220.5-221.5^{\circ} \mathrm{C}\left[n-\mathrm{C}_{6} \mathrm{H}_{14}\right.$ $\left.\mathrm{CHCl}_{3}\right]$. IR (KBr) v: 3400, 2960,1740,1710, 1660, 1590, $1510 \mathrm{~cm}^{-1}$. ${ }^{1} \mathrm{H}-\mathrm{NMR}\left(\mathrm{CDCl}_{3}\right) \delta: 1.04(3 \mathrm{H}, \mathrm{t}, J=7 \mathrm{~Hz}), 1.14$ (two $\left.1.5 \mathrm{H}, \mathrm{s}\right), 1.41(3 \mathrm{H}$, $\mathrm{t}, J=7 \mathrm{~Hz}), 1.80-2.20(2 \mathrm{H}, \mathrm{br} \mathrm{m}), 2.69-2.93(2 \mathrm{H}$, br m), $3.09-4.16(4 \mathrm{H}$, br m), $3.16(2 \mathrm{H}, \mathrm{q}, J=7 \mathrm{~Hz}), 5.24(2 \mathrm{H}, \mathrm{s}), 5.29(1 \mathrm{H}, \mathrm{d}, J=16 \mathrm{~Hz}), 5.73$ $(1 \mathrm{H}, \mathrm{d}, J=16 \mathrm{~Hz}), 7.58(1 \mathrm{H}, \mathrm{dd}, J=2,8 \mathrm{~Hz}), 7.62(1 \mathrm{H}, \mathrm{s}), 7.85(1 \mathrm{H}, \mathrm{d}$, $J=2 \mathrm{~Hz}), 8.21(1 \mathrm{H}, \mathrm{d}, J=8 \mathrm{~Hz}) . \mathrm{MS} m / z: 518\left[\mathrm{M}^{+}\right]$for $\mathrm{C}_{28} \mathrm{H}_{30} \mathrm{~N}_{4} \mathrm{O}_{6}=518$. 6-20: $32 \%$ yield as pale yellow powder, mp $215.5-217^{\circ} \mathrm{C}\left[n-\mathrm{C}_{6} \mathrm{H}_{14}\right.$ $\left.\mathrm{CHCl}_{3}\right]$. IR (KBr) v: 3400, 2960, 1740, 1710, 1660, 1590, $1450 \mathrm{~cm}^{-1}$. ${ }^{1} \mathrm{H}-\mathrm{NMR}\left(\mathrm{CDCl}_{3}\right) \delta: 1.03(3 \mathrm{H}, \mathrm{t}, J=7 \mathrm{~Hz}), 1.32(3 \mathrm{H}, \mathrm{d}, J=7 \mathrm{~Hz}), 1.41$ $(3 \mathrm{H}, \mathrm{t}, J=4 \mathrm{~Hz}), 1.42(3 \mathrm{H}, \mathrm{d}, J=7 \mathrm{~Hz}), 1.80-2.20(2 \mathrm{H}, \mathrm{br} \mathrm{m}), 2.64(1 \mathrm{H}$, $\mathrm{m}), 3.17(2 \mathrm{H}, \mathrm{q}, J=7 \mathrm{~Hz}), 3.27(1 \mathrm{H}, \mathrm{m}), 3.37(1 \mathrm{H}, \mathrm{dd}, J=2,14 \mathrm{~Hz}), 3.52$ $(1 \mathrm{H}, \mathrm{dd}, J=2,14 \mathrm{~Hz}), 3.79(1 \mathrm{H}, \mathrm{m}), 4.35(1 \mathrm{H}, \mathrm{m}), 5.26(2 \mathrm{H}, \mathrm{s}), 5.31(1 \mathrm{H}$ d, $J=16 \mathrm{~Hz}), 5.74(1 \mathrm{H}, \mathrm{d}, J=16 \mathrm{~Hz}), 7.58(1 \mathrm{H}, \mathrm{dd}, J=2,8 \mathrm{~Hz}), 7.66(1 \mathrm{H}$, s), $7.84(1 \mathrm{H}, \mathrm{d}, J=2 \mathrm{~Hz}), 8.23(1 \mathrm{H}, \mathrm{d}, J=8 \mathrm{~Hz}) . \mathrm{MS} \mathrm{m} / \mathrm{z}: 532\left[\mathrm{M}^{+}\right]$for $\mathrm{C}_{29} \mathrm{H}_{32} \mathrm{~N}_{4} \mathrm{O}_{6}=532$.

6-21: $23 \%$ yield as pale yellow powder, mp $216-227^{\circ} \mathrm{C}\left[n-\mathrm{C}_{6} \mathrm{H}_{14}\right.$ $\left.\mathrm{CHCl}_{3}\right]$. IR (KBr) v: $3400,2980,1750,1720,1660,1610,1450 \mathrm{~cm}^{-1}$. ${ }^{1} \mathrm{H}-\mathrm{NMR}\left(\mathrm{CDCl}_{3}\right) \delta: 1.04(3 \mathrm{H}, \mathrm{t}, J=7 \mathrm{~Hz}), 1.14(3 \mathrm{H}, \mathrm{d}, J=7 \mathrm{~Hz}), 1.16$ $(3 \mathrm{H}, \mathrm{d}, J=7 \mathrm{~Hz}), 1.41(3 \mathrm{H}, \mathrm{t}, J=7 \mathrm{~Hz}), 1,80-2.00(2 \mathrm{H}, \mathrm{br} \mathrm{m}), 2.52(1 \mathrm{H}$, $\mathrm{t}, J=12 \mathrm{~Hz}), 2.69(1 \mathrm{H}, \mathrm{t}, J=12 \mathrm{~Hz}), 3.16(2 \mathrm{H}, \mathrm{q}, J=7 \mathrm{~Hz}), 4.15(2 \mathrm{H}, \mathrm{d}$, $J=12 \mathrm{~Hz}), 4.23(2 \mathrm{H}, \mathrm{d}, J=12 \mathrm{~Hz}), 5.26(2 \mathrm{H}, \mathrm{s}), 5.31(1 \mathrm{H}, \mathrm{d}$, $J=16 \mathrm{~Hz}), 5.75(1 \mathrm{H}, \mathrm{d}, J=16 \mathrm{~Hz}), 7.59(1 \mathrm{H}, \mathrm{dd}, J=2,8 \mathrm{~Hz}), 7.64(1 \mathrm{H}$, s), $7.85(1 \mathrm{H}, \mathrm{d}, J=2 \mathrm{~Hz}), 8.22(1 \mathrm{H}, \mathrm{d}, J=8 \mathrm{~Hz})$.
6-22: $36 \%$ yield as pale yellow needles, mp $235-237^{\circ} \mathrm{C}\left[n-\mathrm{C}_{6} \mathrm{H}_{14}\right.$ $\mathrm{CHCl}_{3}$ ]. IR (KBr) v: $3370,2955,1745,1700,1655,1595,1410 \mathrm{~cm}^{-1}$ ${ }^{1} \mathrm{H}-\mathrm{NMR}\left(\mathrm{CDCl}_{3}\right) \delta: 1.04(3 \mathrm{H}, \mathrm{t}, J=7 \mathrm{~Hz}), 1.41(3 \mathrm{H}, \mathrm{t}, J=7 \mathrm{~Hz})$, $1.50-2.00(4 \mathrm{H}, \mathrm{m}), 1.80-2.00(2 \mathrm{H}, \mathrm{m}), 2.34(6 \mathrm{H}, \mathrm{s}), 2.40(1 \mathrm{H}, \mathrm{m}), 2.34$ $(1 \mathrm{H}$, br t, $J=12 \mathrm{~Hz}), 3.11(1 \mathrm{H}$, br t $J=12 \mathrm{~Hz}), 3.16(2 \mathrm{H}, \mathrm{q}, J=7 \mathrm{~Hz}), 3.82$ (1H, br s), $4.32(1 \mathrm{H}, \mathrm{br}), 4.41(1 \mathrm{H}, \mathrm{br}), 5.26(2 \mathrm{H}, \mathrm{s}), 5.31(1 \mathrm{H}, \mathrm{d}, J=16 \mathrm{~Hz})$, $5.75(1 \mathrm{H}, \mathrm{d}, J=16 \mathrm{~Hz}), 7.59(1 \mathrm{H}, \mathrm{dd}, J=2,9 \mathrm{~Hz}), 7.64(1 \mathrm{H}, \mathrm{s}), 7.84(1 \mathrm{H}$, d, $J=2 \mathrm{~Hz}), 8.22(1 \mathrm{H}, \mathrm{d}, J=9 \mathrm{~Hz})$

6-23: $45 \%$ yield as pale yellow needles, mp $236-238^{\circ} \mathrm{C}\left[n-\mathrm{C}_{6} \mathrm{H}_{14}-\right.$ $\left.\mathrm{CHCl}_{3}\right]$. IR (KBr) v: $3385,2955,1745,1710,1655,1595,1410 \mathrm{~cm}^{-1}$. ${ }^{1} \mathrm{H}-\mathrm{NMR}\left(\mathrm{CDCl}_{3}\right) \delta: 1.04(3 \mathrm{H}, \mathrm{t}, J=7 \mathrm{~Hz}), 1.11(6 \mathrm{H}, \mathrm{t}, J=7 \mathrm{~Hz}), 1.41$ $(3 \mathrm{H}, \mathrm{t}, J=7 \mathrm{~Hz}), 1.50-2.00(4 \mathrm{H}, \mathrm{m}), 1.80-2.00(2 \mathrm{H}, \mathrm{m}), 2.66(4 \mathrm{H}, \mathrm{q}$, $J=7 \mathrm{~Hz}), 2.82(1 \mathrm{H}, \mathrm{m}), 2.91(1 \mathrm{H}, \mathrm{br} \mathrm{t}, J=12 \mathrm{~Hz}), 3.07(1 \mathrm{H}, \mathrm{brt}, J=12 \mathrm{~Hz})$, $3.16(2 \mathrm{H}, \mathrm{q}, J=7 \mathrm{~Hz}), 3.80(1 \mathrm{H}, \mathrm{br} \mathrm{s}), 4.36$ (1H, br), 4.45 (1H, br), 5.26 $(2 \mathrm{H}, \mathrm{s}), 5.31(1 \mathrm{H}, \mathrm{d}, J=16 \mathrm{~Hz}), 5.75(1 \mathrm{H}, \mathrm{d}, J=16 \mathrm{~Hz}), 7.59(1 \mathrm{H}, \mathrm{dd}, J=2$, $9 \mathrm{~Hz}), 7.64(1 \mathrm{H}, \mathrm{s}), 7.84(1 \mathrm{H}, \mathrm{d}, J=2 \mathrm{~Hz}), 8.22(1 \mathrm{H}, \mathrm{d}, J=9 \mathrm{~Hz})$.

6-24: $48 \%$ yield as pale yellow needles, mp $196-199^{\circ} \mathrm{C}\left[n-\mathrm{C}_{6} \mathrm{H}_{14}-\right.$ $\mathrm{CHCl}_{3}$ ]. IR (KBr) v: $3395,2945,1745,1715,1655,1600,1455 \mathrm{~cm}^{-1}$. ${ }^{1} \mathrm{H}-\mathrm{NMR}\left(\mathrm{CDCl}_{3}\right) \delta: 0.90(6 \mathrm{H}, \mathrm{t}, J=7 \mathrm{~Hz}), 1.04(3 \mathrm{H}, \mathrm{t}, J=7 \mathrm{~Hz}), 1.41$ $(3 \mathrm{H}, \mathrm{t}, J=7 \mathrm{~Hz}), 1.46(4 \mathrm{H}, \mathrm{sex}, J=7 \mathrm{~Hz}), 1.50-2.00(4 \mathrm{H}, \mathrm{m}), 1.80-2.00$ $(2 \mathrm{H}, \mathrm{m}), 2.45(4 \mathrm{H}, \mathrm{t}, J=7 \mathrm{~Hz}), 2.73(1 \mathrm{H}, \mathrm{m}), 2.88(1 \mathrm{H}, \mathrm{br} \mathrm{t}, J=12 \mathrm{~Hz})$, $3.04(1 \mathrm{H}$, br t $J=12 \mathrm{~Hz}), 3.16(2 \mathrm{H}, \mathrm{q}, J=7 \mathrm{~Hz}), 3.86(1 \mathrm{H}, \mathrm{br} \mathrm{s}), 4.35(1 \mathrm{H}$, br), $4.45(1 \mathrm{H}, \mathrm{br}), 5.25(2 \mathrm{H}, \mathrm{s}), 5.31(1 \mathrm{H}, \mathrm{d}, J=16 \mathrm{~Hz}), 5.75(1 \mathrm{H}, \mathrm{d}$, $J=16 \mathrm{~Hz}), 7.59(1 \mathrm{H}, \mathrm{dd}, J=2,9 \mathrm{~Hz}), 7.65(1 \mathrm{H}, \mathrm{s}), 7.84(1 \mathrm{H}, \mathrm{d}$, $J=2 \mathrm{~Hz}), 8.22(1 \mathrm{H}, \mathrm{d}, J=9 \mathrm{~Hz})$.

6-25: $52 \%$ yield as pale yellow needles, $\mathrm{mp} 203.5-206.5^{\circ} \mathrm{C}\left[n-\mathrm{C}_{6} \mathrm{H}_{14}-\right.$ $\mathrm{CHCl}_{3}$ ]. IR (KBr) $v: 3390,2940,1750,1715,1665,1610,1455 \mathrm{~cm}^{-1}$. ${ }^{1} \mathrm{H}-\mathrm{NMR}\left(\mathrm{CDCl}_{3}\right) \delta: 0.93(6 \mathrm{H}, \mathrm{t}, J=7 \mathrm{~Hz}), 1.04(3 \mathrm{H}, \mathrm{t}, J=7 \mathrm{~Hz}), 1.33$ $(4 \mathrm{H}, \mathrm{sex}, J=7 \mathrm{~Hz}), 1.35-1.50(4 \mathrm{H}, \mathrm{m}), 1.41(3 \mathrm{H}, \mathrm{t}, J=7 \mathrm{~Hz}), 1.16$ $(4 \mathrm{H}$, sex, $J=7 \mathrm{~Hz}), 1.50-2.00(4 \mathrm{H}, \mathrm{m}), 1.80-2.00(2 \mathrm{H}, \mathrm{m}), 2.48(4 \mathrm{H}, \mathrm{t}$, $J=7 \mathrm{~Hz}), 2.71(1 \mathrm{H}, \mathrm{m}), 2.88(1 \mathrm{H}$, br t,$J=13 \mathrm{~Hz}), 3.04(1 \mathrm{H}$, br t, $J=$ $13 \mathrm{~Hz}), 3.16(2 \mathrm{H}, \mathrm{q}, J=7 \mathrm{~Hz}), 3.85(1 \mathrm{H}, \mathrm{br} \mathrm{s}), 4.35(1 \mathrm{H}, \mathrm{br}), 4.44(1 \mathrm{H}$, br), $5.26(2 \mathrm{H}, \mathrm{s}), 5.31(1 \mathrm{H}, \mathrm{d}, J=16 \mathrm{~Hz}), 5.75(1 \mathrm{H}, \mathrm{d}, J=16 \mathrm{~Hz}), 7.59(1 \mathrm{H}$, dd, $J=2,9 \mathrm{~Hz}), 7.65(1 \mathrm{H}, \mathrm{s}), 7.84(1 \mathrm{H}, \mathrm{d}, J=2 \mathrm{~Hz}), 8.22(1 \mathrm{H}, \mathrm{d}, J=9 \mathrm{~Hz})$.

6-26: $58.2 \%$ yield as pale yellow powder, mp $219-223^{\circ} \mathrm{C}\left[n-\mathrm{C}_{16} \mathrm{H}_{14}\right.$ $\left.\mathrm{CHCl}_{3}\right]$. IR (KBr) v: $3400,2955,1745,1715,1655,1600,1450 \mathrm{~cm}^{-1}$. ${ }^{1} \mathrm{H}-\mathrm{NMR}\left(\mathrm{CDCl}_{3}\right) \delta: 1.30(3 \mathrm{H}, \mathrm{t}, J=7 \mathrm{~Hz}), 1.40(3 \mathrm{H}, \mathrm{t}, J=7 \mathrm{~Hz}), 1.66$ $(2 \mathrm{H}$, br t,$J=7 \mathrm{~Hz}), 1.84(4 \mathrm{H}, \mathrm{br} \mathrm{s}), 1.80-2.00(2 \mathrm{H}, \mathrm{m}), 1.95-2.20(2 \mathrm{H}$, br s), $2.30(1 \mathrm{H}, \mathrm{br}), 2.64(4 \mathrm{H}$, br s), $3.04(1 \mathrm{H}, \mathrm{br}), 3.15(2 \mathrm{H}, \mathrm{q}, J=7 \mathrm{~Hz})$, 3.18 (1H, br), 3.95 (1H, br s), $4.22(1 \mathrm{H}$, brd, $J=14 \mathrm{~Hz}), 4.33$ (1H, br d, $J=14 \mathrm{~Hz}), 5.25(2 \mathrm{H}, \mathrm{s}), 5.30(1 \mathrm{H}, \mathrm{d}, J=16 \mathrm{~Hz}), 5.74(1 \mathrm{H}, \mathrm{d}, J=16 \mathrm{~Hz})$, $7.57(1 \mathrm{H}, \mathrm{dd}, J=2,9 \mathrm{~Hz}), 7.64(1 \mathrm{H}, \mathrm{s}), 7.82(1 \mathrm{H}, \mathrm{d}, J=2 \mathrm{~Hz}), 8.22(1 \mathrm{H}$, d, $J=9 \mathrm{~Hz}$ ).

6-27: $79.8 \%$ yield as pale yellow powder, mp $222-223^{\circ} \mathrm{C}\left[n-\mathrm{C}_{6} \mathrm{H}_{14}\right.$ $\mathrm{CHCl}_{3}$ ]. IR (KBr) v: $3420,2930,1745,1715,1655,1600,1412 \mathrm{~cm}^{-11} \mathrm{H}$ NMR (DMSO- $\left.d_{6}\right) \delta: 0.90(3 \mathrm{H}, \mathrm{t}, J=7 \mathrm{~Hz}), 1.28(3 \mathrm{H}, \mathrm{t}, J=8 \mathrm{~Hz}), 1.38$ $(2 \mathrm{H}, \mathrm{br}), 1.49(6 \mathrm{H}, \mathrm{br}), 1.78(2 \mathrm{H}, \mathrm{brd}), 1.85(1 \mathrm{H}, \mathrm{q}, J=7 \mathrm{~Hz}), 1.90(1 \mathrm{H}$, q, $J=7 \mathrm{~Hz}), 2.46(5 \mathrm{H}, \mathrm{br}), 2.89(1 \mathrm{H}, \mathrm{br} \mathrm{t}), 3.05(1 \mathrm{H}$, br t $), 3.14(2 \mathrm{H}, \mathrm{q}$, $J=8 \mathrm{~Hz}), 4.31$ (1H, brd), $4.24(1 \mathrm{H}$, br d), $5.24(2 \mathrm{H}, \mathrm{s}), 5.42(2 \mathrm{H}, \mathrm{s}), 6.51$ $(1 \mathrm{H}, \mathrm{s}), 7.29(1 \mathrm{H}, \mathrm{s}), 7.60(1 \mathrm{H}, \mathrm{dd}, J=3,9 \mathrm{~Hz}), 7.90(1 \mathrm{H}, \mathrm{d}, J=3 \mathrm{~Hz})$, $8.09(1 \mathrm{H}, \mathrm{d}, J=9 \mathrm{~Hz})$. Anal. Calcd for $\mathrm{C}_{33} \mathrm{H}_{38} \mathrm{~N}_{4} \mathrm{O}_{6}: \mathrm{C}, 61.88 ; \mathrm{H}, 6.39$; N, 9.38. Found: C, 65.28; H, 6.39; N, 9.38.

6-28: $52.4 \%$ yield as pale yellow powder, mp $221.5-223^{\circ} \mathrm{C}\left[n-C_{6} \mathrm{H}_{14}-\right.$ $\left.\mathrm{CHCl}_{3}\right]$. IR (KBr) v: $3400,2950,1745,1710,1655,1595,1410 \mathrm{~cm}^{-1}$ ${ }^{1} \mathrm{H}-\mathrm{NMR}\left(\mathrm{CDCl}_{3}\right) \delta: 1.04(3 \mathrm{H}, \mathrm{t}, J=7 \mathrm{~Hz}), 1.40(3 \mathrm{H}, \mathrm{t}, J=7 \mathrm{~Hz}), 1.61$ $(2 \mathrm{H}$, br t $J=4 \mathrm{~Hz}), 1.80-2.00(2 \mathrm{H}, \mathrm{m}), 1.90-2.05(2 \mathrm{H}, \mathrm{m}), 2.46(1 \mathrm{H}$, $\mathrm{m}), 2.61(4 \mathrm{H}, \mathrm{t}, J=4 \mathrm{~Hz}), 2.96(1 \mathrm{H}, \mathrm{br}), 3.13(1 \mathrm{H}, \mathrm{br}), 3.16(2 \mathrm{H}, \mathrm{q}, J=7 \mathrm{~Hz})$, $3.76(4 \mathrm{H}, \mathrm{t}, J=4 \mathrm{~Hz}), 3.85(1 \mathrm{H}, \mathrm{br} \mathrm{s}), 4.32(1 \mathrm{H}, \mathrm{d}, J=12 \mathrm{~Hz}), 4.42(1 \mathrm{H}, \mathrm{d}$, $J=4 \mathrm{~Hz}), 5.26(2 \mathrm{H}, \mathrm{s}), 5.31(1 \mathrm{H}, \mathrm{d}, J=16 \mathrm{~Hz}), 5.75(1 \mathrm{H}, \mathrm{d}, J=16 \mathrm{~Hz})$, $7.58(1 \mathrm{H}$, dd, $J=2,9 \mathrm{~Hz}), 7.65(1 \mathrm{H}, \mathrm{s}), 7.83(1 \mathrm{H}, \mathrm{d}, J=2 \mathrm{~Hz}), 8.22(1 \mathrm{H}$, d, $J=9 \mathrm{~Hz}$ ).

6-29: $60.8 \%$ yield as pale yellow powder, $\mathrm{mp} 159-162^{\circ} \mathrm{C}\left[n-\mathrm{C}_{6} \mathrm{H}_{14}-\right.$ $\mathrm{CHCl}_{3}$ ]. IR (KBr) v: 3420, 2940,1745, 1720, 1656,1600, $1405 \mathrm{~cm}^{-1}$. ${ }^{1} \mathrm{H}-\mathrm{NMR}\left(\mathrm{CDCl}_{3}\right) \delta: 1.03(3 \mathrm{H}, \mathrm{t}, J=7 \mathrm{~Hz}), 1.41(3 \mathrm{H}, \mathrm{t}, J=7 \mathrm{~Hz})$, $1.08-2.15(6 \mathrm{H}, \mathrm{m}), 2.04(3 \mathrm{H}, \mathrm{s}), 3.00-3.20(6 \mathrm{H}, \mathrm{m}), 4.12(2 \mathrm{H}, \mathrm{q}, J=7 \mathrm{~Hz})$, $5.25(2 \mathrm{H}, \mathrm{s}), 5.32(1 \mathrm{H}, \mathrm{d}, J=16 \mathrm{~Hz}), 5.75(1 \mathrm{H}, \mathrm{d}, J=16 \mathrm{~Hz}), 7.59(1 \mathrm{H}$, dd, $J=2,8 \mathrm{~Hz}), 7.65(1 \mathrm{H}, \mathrm{s}), 7.85(1 \mathrm{H}, \mathrm{d}, J=2 \mathrm{~Hz}), 8.22(1 \mathrm{H}, \mathrm{d}, J=8 \mathrm{~Hz})$. 6-30: $31 \%$ yield as pale yellow powder, $\mathrm{mp} 222-223.5^{\circ} \mathrm{C}\left[n-\mathrm{C}_{6} \mathrm{H}_{14}-\right.$ $\mathrm{CHCl}_{3}$ ]. IR (KBr) v: $3400,2970,1750,1700,1660,1590,1460 \mathrm{~cm}^{-1}$. ${ }^{1} \mathrm{H}-\mathrm{NMR}\left(\mathrm{CDCl}_{3}\right) \delta: 1.03(3 \mathrm{H}, \mathrm{t}, J=7 \mathrm{~Hz}), 1.43(3 \mathrm{H}, \mathrm{t}, J=7 \mathrm{~Hz}), 1.80$ $2.00(4 \mathrm{H}, \mathrm{m}), 2.98-3.00(2 \mathrm{H}, \mathrm{m}), 3.04-3.10(2 \mathrm{H}, \mathrm{m}), 3.16(2 \mathrm{H}, \mathrm{q}, J=$ $7 \mathrm{~Hz}), 3.64(2 \mathrm{H}, \mathrm{t}, J=4.5 \mathrm{~Hz}), 3.69(2 \mathrm{H}, \mathrm{t}, J=4.5 \mathrm{~Hz}), 5.24(2 \mathrm{H}, \mathrm{s}), 5.29$ $(1 \mathrm{H}, \mathrm{d}, J=16 \mathrm{~Hz}), 5.74(1 \mathrm{H}, \mathrm{d}, J=16 \mathrm{~Hz}), 7.59(1 \mathrm{H}, \mathrm{dd}, J=2,8 \mathrm{~Hz})$, $7.62(1 \mathrm{H}, \mathrm{s}), 7.78(1 \mathrm{H}, \mathrm{d}, J=2 \mathrm{~Hz}), 8.21(1 \mathrm{H}, \mathrm{d}, J=8 \mathrm{~Hz})$

6-31: $39 \%$ yield as pale yellow powder, $\mathrm{mp} 220-222.5^{\circ} \mathrm{C}\left[n-\mathrm{C}_{6} \mathrm{H}_{14}{ }^{-}\right.$ 
$\mathrm{CHCl}_{3}$ ]. IR (KBr) v: 3400, 1750, 1710, 1660, 1590, $1460 \mathrm{~cm}^{-1} \cdot{ }^{1} \mathrm{H}-\mathrm{NMR}$ $\left(\mathrm{CDCl}_{3}\right) \delta: 1.04(3 \mathrm{H}, \mathrm{t}, J=7 \mathrm{~Hz}), 1.41(3 \mathrm{H}, \mathrm{t}, J=7 \mathrm{~Hz}), 1.80-2.00(4 \mathrm{H}$, $\mathrm{m}$ ), 2.42, 2.44 (two $1.5 \mathrm{H}, \mathrm{s}), 2.66-2.77(4 \mathrm{H}, \mathrm{m}), 3.14(2 \mathrm{H}, \mathrm{q}, J=7 \mathrm{~Hz}$ ), $3.68-3.81(4 \mathrm{H}, \mathrm{m}), 5.24(2 \mathrm{H}, \mathrm{s}), 5.29(1 \mathrm{H}, \mathrm{d}, J=16 \mathrm{~Hz}), 5.73(1 \mathrm{H}, \mathrm{d}$, $J=16 \mathrm{~Hz}) ; 7.59$ (1H, dd, $J=2,8 \mathrm{~Hz}), 7.62(1 \mathrm{H}, \mathrm{s}), 7.86(1 \mathrm{H}, \mathrm{d}, J=2 \mathrm{~Hz})$, $8.21(1 \mathrm{H}, \mathrm{d}, J=8 \mathrm{~Hz})$. $\mathrm{MS} m / z: 532\left[\mathrm{M}^{+}\right]$for $\mathrm{C}_{29} \mathrm{H}_{32} \mathrm{~N}_{4} \mathrm{O}_{6}=532$.

6-32: $48.9 \%$ yield as pale yellow powder, $\mathrm{mp} 202-203.1{ }^{\circ} \mathrm{C}\left[n-\mathrm{C}_{6} \mathrm{H}_{14}\right.$ $\mathrm{CHCl}_{3}$ ]. ${ }^{1} \mathrm{H}-\mathrm{NMR}\left(\mathrm{CDCl}_{3}\right) \delta: 1.03(3 \mathrm{H}, \mathrm{t}, J=7 \mathrm{~Hz}), 1.39(3 \mathrm{H}, \mathrm{t}, J=7 \mathrm{~Hz})$, $1.84(2 \mathrm{H}, \mathrm{q}, J=7 \mathrm{~Hz}), 2.36(6 \mathrm{H}, \mathrm{br} \mathrm{s}), 2.64(2 \mathrm{H}, \mathrm{t}, J=7 \mathrm{~Hz}), 3.09(1.5 \mathrm{H}$, s), $3.22(1.5 \mathrm{H}, \mathrm{s}), 3.16(2 \mathrm{H}, \mathrm{q}, J=7 \mathrm{~Hz}), 3.58(2 \mathrm{H}, \mathrm{t}, J=7 \mathrm{~Hz}), 5.24(2 \mathrm{H}$, s), $5.27(1 \mathrm{H}, \mathrm{d}, J=16 \mathrm{~Hz}), 5.75(1 \mathrm{H}, \mathrm{d}, J=16 \mathrm{~Hz}), 7.26(1 \mathrm{H}, \mathrm{s}), 7.41(1 \mathrm{H}$, dd, $J=2,9 \mathrm{~Hz}), 7.62(1 \mathrm{H}, \mathrm{d}, J=2 \mathrm{~Hz}), 8.09(1 \mathrm{H}, \mathrm{d}, J=9 \mathrm{~Hz})$.

6-33: $28 \%$ yield as pale yellow needles, mp $172-175^{\circ} \mathrm{C}\left[n-\mathrm{C}_{6} \mathrm{H}_{14}\right.$ $\mathrm{CHCl}_{3}$ ]. IR(KBr)v: $3400,2970,1745,1715,1660,1610,1460 \mathrm{~cm}^{-1} \cdot{ }^{1} \mathrm{H}-$ $\operatorname{NMR}\left(\mathrm{CDCl}_{3}\right) \delta: 1.04(3 \mathrm{H}, \mathrm{t}, J=7 \mathrm{~Hz}), 1.07(6 \mathrm{H}, \mathrm{t}, J=7 \mathrm{~Hz}), 1.40$ $(3 \mathrm{H}, \mathrm{t}, J=7 \mathrm{~Hz}), 1.80-2.00(2 \mathrm{H}, \mathrm{m}), 2.60(4 \mathrm{H}, \mathrm{q}, J=7 \mathrm{~Hz}), 2.74(2 \mathrm{H}, \mathrm{m})$, $2.74(2 \mathrm{H}, \mathrm{m}), 3.09(1.5 \mathrm{H}, \mathrm{br} \mathrm{s}), 3.21(1.5 \mathrm{H}, \mathrm{br} \mathrm{s}), 3.15(2 \mathrm{H}, \mathrm{q}, J=7 \mathrm{~Hz})$, $5.29(1 \mathrm{H}, \mathrm{d}, J=16 \mathrm{~Hz}), 5.73(1 \mathrm{H}, \mathrm{d}, J=16 \mathrm{~Hz}), 7.59(1 \mathrm{H}, \mathrm{dd}, J=2,8 \mathrm{~Hz})$, $7.62(1 \mathrm{H}, \mathrm{s}), 7.85(1 \mathrm{H}, \mathrm{d}, J=2 \mathrm{~Hz}), 8.20(1 \mathrm{H}, \mathrm{d}, J=8 \mathrm{~Hz}) . \mathrm{MS} \mathrm{m} / z: 548$ $\left[\mathrm{M}^{+}\right]$for $\mathrm{C}_{30} \mathrm{H}_{36} \mathrm{~N}_{4} \mathrm{O}_{6}=548$.

6-34: $17 \%$ yield as pale yellow powder, $\mathrm{mp} 166-169^{\circ} \mathrm{C}\left[n-\mathrm{C}_{6} \mathrm{H}_{14}-\right.$ $\mathrm{CHCl}_{3}$ ]. IR (KBr) v: $3400,2965,1750,1715,1650,1610,1460 \mathrm{~cm}^{-1}$. ${ }^{1} \mathrm{H}-\mathrm{NMR}\left(\mathrm{CDCl}_{3}\right) \delta: 1.04(3 \mathrm{H}, \mathrm{t}, J=7 \mathrm{~Hz}), 1.07(3 \mathrm{H}, \mathrm{t}, J=7 \mathrm{~Hz}), 1.08$ $(3 \mathrm{H}, \mathrm{t}, J=7 \mathrm{~Hz}), 1.26(3 \mathrm{H}, \mathrm{t}, J=7 \mathrm{~Hz}), 1.34(3 \mathrm{H}, \mathrm{t}, J=7 \mathrm{~Hz}), 1.41(3 \mathrm{H}, \mathrm{t}$, $J=7 \mathrm{~Hz}), 1.80-2.00(2 \mathrm{H}, \mathrm{m}), 2.61(4 \mathrm{H}, \mathrm{m}), 2.70-2.80(2 \mathrm{H}, \mathrm{m}), 3.16(2 \mathrm{H}$, $\mathrm{q}, J=7 \mathrm{~Hz}), 3.40-3.60(2 \mathrm{H}, \mathrm{m}), 5.26(2 \mathrm{H}, \mathrm{s}), 5.31(1 \mathrm{H}, \mathrm{d}, J=16 \mathrm{~Hz}), 5.75$ $(1 \mathrm{H}, \mathrm{d}, J=16 \mathrm{~Hz}), 7.60(1 \mathrm{H}, \mathrm{dd}, J=2,8 \mathrm{~Hz}), 7.64(1 \mathrm{H}, \mathrm{s}), 7.83(1 \mathrm{H}, \mathrm{d}$, $J=2 \mathrm{~Hz}), 8.22(1 \mathrm{H}, \mathrm{d}, J=8 \mathrm{~Hz})$.

6-35: 6\% yield as pale yellow syrup. IR $\left(\mathrm{CHCl}_{3}\right) v: 3400,2955,1800$, $1730,1650,1550,1510,1460 \mathrm{~cm}^{-1} .{ }^{1} \mathrm{H}-\mathrm{NMR}\left(\mathrm{CDCl}_{3}\right) \delta: 0.98(3 \mathrm{H}, \mathrm{t}$, $J=7 \mathrm{~Hz}), 1.00-1.10(6 \mathrm{H}, \mathrm{m}), 1.04(3 \mathrm{H}, \mathrm{t}, J=7 \mathrm{~Hz}), 1.42(3 \mathrm{H}, \mathrm{t}, J=7 \mathrm{~Hz})$, $1.80-2.00(2 \mathrm{H}, \mathrm{m}), 3.15(2 \mathrm{H}, \mathrm{q}, J=7 \mathrm{~Hz}), 3.40-3.50(4 \mathrm{H}, \mathrm{m}), 3.50-3.70$ $(4 \mathrm{H}, \mathrm{m}), 3.87(2 \mathrm{H}, \mathrm{t}, J=7 \mathrm{~Hz}), 4.10(2 \mathrm{H}, \mathrm{t}, J=7 \mathrm{~Hz}), 5.24(2 \mathrm{H}, \mathrm{s}), 5.29$ $(1 \mathrm{H}, \mathrm{d}, J=16 \mathrm{~Hz}), 5.73(1 \mathrm{H}, \mathrm{d}, J=16 \mathrm{~Hz}), 7.58(1 \mathrm{H}, \mathrm{dd}, J=2,8 \mathrm{~Hz}), 7.62$ $(1 \mathrm{H}, \mathrm{s}), 7.84(1 \mathrm{H}, \mathrm{d}, J=2 \mathrm{~Hz}), 8.20(1 \mathrm{H}, \mathrm{d}, J=8 \mathrm{~Hz})$.

6-36: $8 \%$ yield as pale yellow syrup. IR $\left(\mathrm{CHCl}_{3}\right) v$ : $3370,2950,1745$, $1715,1655,1460 \mathrm{~cm}^{-1} .{ }^{1} \mathrm{H}-\mathrm{NMR}\left(\mathrm{CDCl}_{3}\right) \delta: 0.80-4.40(23 \mathrm{H}, \mathrm{m})$, $0.85-1.15(5 \mathrm{H}, \mathrm{m}), 1.80-2.00(2 \mathrm{H}, \mathrm{m}), 5.28(2 \mathrm{H}, \mathrm{s}), 5.35(1 \mathrm{H}, \mathrm{d}$, $J=16 \mathrm{~Hz}), 5.69(1 \mathrm{H}, \mathrm{d}, J=16 \mathrm{~Hz}), 7.69(1 \mathrm{H}, \mathrm{dd}, J=2,8 \mathrm{~Hz}), 8.12(1 \mathrm{H}, \mathrm{d}$, $J=2 \mathrm{~Hz}), 8.13(1 \mathrm{H}, \mathrm{s}), 8.55(1 \mathrm{H}, \mathrm{d}, J=8 \mathrm{~Hz})$.

Antitumor Activity of Derivatives 6 on L1210 Leukemia, Test Method (Table I) L1210 leukemia cells $\left(10^{5}\right)$ were implanted intraperitoneally (i.p.) in 7 week old $\mathrm{CDF}_{1}$ female mice on day 0 , and 6 mice were used at the each dose. The samples were administered i.p. on days 1,5 , and 9. The control mice were injected with saline. Cured mice were calculated on day 40.

Antitumor Activity of the Selected Derivatives against Acites Tumors, Test Method (Table II) An aliquot of each suspension (P338, $1.7 \times 10^{6}$ cell $/ \mathrm{ml}, \mathrm{L} 1210,3 \times 10^{5} \mathrm{cell} / \mathrm{ml}$; B16, $\left.2 \times 10^{6} \mathrm{cell} / \mathrm{ml}\right)$ was implanted i.p. in 7 week old female mice $\left(\mathrm{CDF}_{1}\right.$ for P388 and L1210; C57BL/6 for B16) on day 0 . The sample were administered i.p., p.o., and i.v., and the control mice were injected with saline. Cured mice were observed on day 40 for P388 and L1210, day 60 for B16.

Antitumor Activity of the Selected Derivatives against Solid Tumors, Test Method A $0.1 \mathrm{ml}$ aliquot of each tumor suspension $\left(\mathrm{S} 180,1 \times 10^{6} \mathrm{cells} / \mathrm{ml}\right.$; Meth $\mathrm{A}, 1 \times 10^{5} \mathrm{cells} / \mathrm{ml}$ ) was implanted subcutaneously in 7 week old female mice (ICR for S180 and BALB/c for Meth A) on day 0 . The samples were administered i.v. or p.o. on days indicated in Table III. Inhibition rates and cured mice were calculated on day 21 .

CPT-11 (+)-(4S)-4,11-Diethyl-4-hydroxy-9-[(4-piperidinopiperidino)carbonyloxy]-1 $H$-pyrano $\left[3^{\prime}, 4^{\prime}: 6,7\right]$ indolizino $[1,2-b]$ quinoline-3, 14 $(4 \mathrm{H}, 12 \mathrm{H})$-dione hydrochloride trihydrate

a) Preparation: To a suspension of $6-27(1000 \mathrm{~g})$ in distilled water $(10.71), 5 \mathrm{~N} \mathrm{HCl}(0.41)$ was added and the mixture was warmed at $70^{\circ} \mathrm{C}$. To the solution activated carbon $(200 \mathrm{~g})$ was added and the mixture was stirred for $30 \mathrm{~min}$ at $70^{\circ} \mathrm{C}$. After cooling the mixture to an ambient temperature, the mixture was stirred with AcOEt (3.71). The mixture was filtered through a Celite pad by suction and the aqueous layer was separated and passed through a membrane filter $(0.22 \mu \mathrm{m})$ and then the filtrate was condensed to about 91 in vacuo. To the solution, $5 \mathrm{~N} \mathrm{HCl}(75 \mathrm{ml})$ was added and the solution was stirred for $40 \mathrm{~h}$ at an ambient temperature. The precipitate was collected and the material was dried in vacuo. The dried material was placed in a $75 \%$ relative humidity chamber for $70 \mathrm{~h}$.

b) Structural Determination of CPT-11: Slightly pale yellow needles, $\mathrm{mp} 256.5^{\circ} \mathrm{C}\left[\mathrm{H}_{2} \mathrm{O}\right]$. UV (EtOH) $\lambda \mathrm{nm}(\varepsilon): 221$ (53800), 254 (36600), 359 (26200), $372(25300) .[\alpha]_{\mathrm{D}}^{20}+67.7^{\circ}(c=1$, water). IR (KBr) $v: 3376(\mathrm{O}-\mathrm{H})$,
2630, $2546\left(\mathrm{NH}^{+}\right), 1748$ (lactone carbonyl), 1688 (carbamate carbonyl), 1663 (pyridone carbonyl), 1613 (quinoline $\mathrm{C}=\mathrm{N}$ ), $1568(\mathrm{C}=\mathrm{C}) \mathrm{cm}^{-1}$. ${ }^{1} \mathrm{H}-\mathrm{NMR}$ (DMSO- $\left.d_{6}, 90^{\circ} \mathrm{C}\right) \delta: 0.92\left(3 \mathrm{H}, \mathrm{t}, J=7 \mathrm{~Hz}, \mathrm{C}_{20}-\mathrm{CH}_{2} \mathrm{CH}_{3}\right), 1.33$ $\left(3 \mathrm{H}, \mathrm{t}, J=8 \mathrm{~Hz}, \mathrm{C}_{7}-\mathrm{CH}_{2} \mathrm{CH}_{3}\right), 1.47$ (1H, q-like, $\left.\mathrm{C}_{4},-\mathrm{H}_{\mathrm{ax}}\right), 1.73(1 \mathrm{H}, \mathrm{d}-\mathrm{like}$,

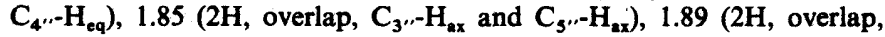
$\mathrm{C}_{3},-\mathrm{H}_{2 \mathrm{x}}$ and $\left.\mathrm{C}_{5},-\mathrm{H}_{\mathrm{ax}}\right), 1.94\left(2 \mathrm{H}, \mathrm{q}, J=7 \mathrm{~Hz}, \mathrm{C}_{20}-\mathrm{CH}_{2}\right), 2.01(2 \mathrm{H}, \mathrm{q}-$ like,

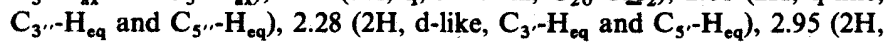

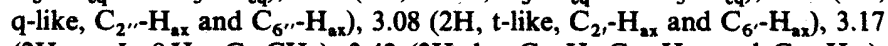
$\left(2 \mathrm{H}, \mathrm{q}, J=8 \mathrm{~Hz}, \mathrm{C}_{7}-\mathrm{CH}_{2}\right), 3.42\left(3 \mathrm{H}, \mathrm{br}, \mathrm{C}_{4},-\mathrm{H}, \mathrm{C}_{2},-\mathrm{H}_{\text {eq }}\right.$ and $\left.\mathrm{C}_{6},-\mathrm{H}_{\mathrm{eq}}\right)$, $4.31\left(2 \mathrm{H}, \mathrm{d}\right.$-like, $\mathrm{C}_{2},-\mathrm{H}_{\mathrm{eq}}$ and $\left.\mathrm{C}_{6},-\mathrm{H}_{\mathrm{eq}}\right), 5.27\left(2 \mathrm{H}, \mathrm{s}, \mathrm{C}_{5}-\mathrm{H}_{2}\right), 5.36(1 \mathrm{H}, \mathrm{d}$, $\left.J=17 \mathrm{~Hz}, \mathrm{C}_{17}-\mathrm{H}_{\mathrm{ax}}\right), 5.45\left(1 \mathrm{H}, \mathrm{d}, J=17 \mathrm{~Hz}, \mathrm{C}_{17}-\mathrm{H}_{\mathrm{eq}}\right), 7.34\left(1 \mathrm{H}, \mathrm{s}, \mathrm{C}_{14}-\mathrm{H}\right)$, $7.65\left(1 \mathrm{H}, \mathrm{dd}, J=3,9 \mathrm{~Hz}, \mathrm{C}_{11}-\mathrm{H}\right), 7.95\left(1 \mathrm{H}, \mathrm{dd}, J=3 \mathrm{~Hz}, \mathrm{C}_{9}-\mathrm{H}\right), 8.13(1 \mathrm{H}$, $\left.\mathrm{d}, J=9 \mathrm{~Hz}, \mathrm{C}_{12}-\mathrm{H}\right), 11.10\left(1 \mathrm{H}, \mathrm{brs}, \mathrm{N}^{+}-\mathrm{H}\right) .{ }^{13} \mathrm{C}-\mathrm{NMR}$ (DMSO- $d_{6}, 90^{\circ} \mathrm{C}$ ) $\delta: 7.6\left(\mathrm{q}, \mathrm{C}_{20}-\mathrm{CH}_{2} \mathrm{CH}_{3}\right), 13.5\left(\mathrm{q}, \mathrm{C}_{7}-\mathrm{CH}_{2} \mathrm{CH}_{3}\right), 21.7\left(\mathrm{t}, \mathrm{C}_{4}^{\prime \prime}\right), 22.2(\mathrm{t}$, $\left.\mathrm{C}_{7}-\mathrm{CH}_{2} \mathrm{CH}_{3}\right), 22.4\left(\mathrm{t}, \mathrm{C}_{3^{\prime \prime}}\right.$ and $\left.\mathrm{C}_{5^{\prime \prime}}\right), 25.7\left(\mathrm{t}, \mathrm{C}_{3^{\prime}}\right.$ and $\left.\mathrm{C}_{5^{\prime}}\right), 31.0(\mathrm{t}$, $\left.\mathrm{C}_{20}-\mathrm{CH}_{2} \mathrm{CH}_{3}\right), 42.9\left(\mathrm{t}, \mathrm{C}_{2^{\prime}}\right.$ and $\left.\mathrm{C}_{6^{\prime}}\right), 49.2\left(\mathrm{t}, \mathrm{C}_{2^{\prime \prime}}\right.$ and $\left.\mathrm{C}_{6^{\prime \prime}}\right), 49.4\left(\mathrm{t}, \mathrm{C}_{5}\right)$, $62.2\left(\mathrm{~d}, \mathrm{C}_{4}\right), 65.5\left(\mathrm{t}, \mathrm{C}_{17}\right), 72.4\left(\mathrm{~s}, \mathrm{C}_{20}\right), 96.6\left(\mathrm{~d}, \mathrm{C}_{14}\right), 114.6\left(\mathrm{~d}, \mathrm{C}_{9}\right), 119.0$ $\left(\mathrm{s}, \mathrm{C}_{16}\right), 125.5\left(\mathrm{~d}, \mathrm{C}_{11}\right), 127.1\left(\mathrm{~s}, \mathrm{C}_{8}\right), 128.2\left(\mathrm{~s}, \mathrm{C}_{6}\right), 131.0\left(\mathrm{~d}, \mathrm{C}_{12}\right), 145.2$ $\left(\mathrm{s}, \mathrm{C}_{7}\right), 146.0\left(\mathrm{~s}, \mathrm{C}_{3}\right), 146.5\left(\mathrm{~s}, \mathrm{C}_{13}\right), 150.0\left(\mathrm{~s}, \mathrm{C}_{10}\right.$ and/or $\left.\mathrm{C}_{1 \mathrm{~s}}\right), 150.1(\mathrm{~s}$, $\mathrm{C}_{15}$ and/or $\mathrm{C}_{10}$ ), $151.8\left(\mathrm{~s}, \mathrm{C}_{2}\right.$ ), 152.6 (s, carbamate carbonyl), 156.9 (s, pyridone carbonyl), 172.1 (s, lactone carbonyl). MS $m / z$ : 586.2786 for

TABLE IV. Fractional Atomic Coordinates and Isotopic Thermal Parameters of CPT-11

\begin{tabular}{|c|c|c|c|c|}
\hline Atom & $X$ & $Y$ & $z$ & $B_{\text {eq }}$ \\
\hline $\mathrm{Cl}(1)$ & $0.5106(3)$ & $0.2653(1)$ & $0.1492(7)$ & $5.89(16)$ \\
\hline $\mathbf{N}(2)$ & $0.8520(10)$ & $0.3943(2)$ & $1.6368(20)$ & $3.16(38)$ \\
\hline$N(3)$ & 0.3955 (11) & $0.3497(3)$ & $0.8631(21)$ & $3.61(41)$ \\
\hline N(4) & $0.3296(10)$ & $0.2694(3)$ & $0.4931(21)$ & $3.06(38)$ \\
\hline$N(5)$ & $0.8362(11)$ & $0.4438(2)$ & $2.0741(21)$ & $3.26(40)$ \\
\hline$O(6)$ & $0.3906(8)$ & $0.3653(3)$ & 1.2029 (19) & $3.88(35)$ \\
\hline$O(7)$ & 0.5485 (9) & 0.3680 (3) & $1.0176(18)$ & $4.68(41)$ \\
\hline$O(8)$ & $0.8177(11)$ & $0.4750(2)$ & $2.3576(22)$ & $4.88(39)$ \\
\hline$O(9)$ & $1.1280(12)$ & 0.4494 ( 3$)$ & $2.5755(19)$ & $5.62(46)$ \\
\hline$O(10)$ & $1.2702(14)$ & $0.4176(4)$ & $2.5581(23)$ & $8.15(61)$ \\
\hline$O(11)$ & $1.1818(11)$ & $0.3897(3)$ & $2.2213(27)$ & $6.01(50)$ \\
\hline$O(12)$ & $0.0185(10)$ & $0.3480(3)$ & $0.7072(22)$ & $6.19(44)$ \\
\hline$O(13)$ & $-0.0168(14)$ & $0.3044(4)$ & $0.0060(23)$ & $8.84(61)$ \\
\hline$O(14)$ & $0.0864(12)$ & 0.3329 ( 3$)$ & $0.3136(26)$ & $7.14(50)$ \\
\hline$C(15)$ & 0.7699 (14) & $0.3896(3)$ & $1.4874(26)$ & $2.85(46)$ \\
\hline$C(16)$ & $0.6155(13)$ & $0.3757(4)$ & $1.1831(26)$ & $3.34(52)$ \\
\hline$C(17)$ & $0.9987(16)$ & $0.4144(4)$ & $2.0119(25)$ & $3.13(49)$ \\
\hline $\mathrm{C}(18)$ & $0.7248(14)$ & $0.4300(3)$ & $1.8046(26)$ & $3.11(47)$ \\
\hline C (19) & $0.6650(15)$ & 0.4041 ( 3$)$ & $1.4965(26)$ & $3.15(48)$ \\
\hline$C(20)$ & $0.6437(13)$ & $0.4248(3)$ & $1.6609(30)$ & $3.26(46)$ \\
\hline$C(21)$ & 0.2739 (14) & $0.3074(4)$ & $0.7722(28)$ & $3.44(51)$ \\
\hline$C(22)$ & $0.4609(16)$ & $0.3468(5)$ & $0.6659(31)$ & $4.58(59)$ \\
\hline C (23) & $0.4360(12)$ & $0.3614(4)$ & $1.0427(34)$ & $3.16(45)$ \\
\hline C (24) & 0.8965 (12) & $0.4230(3)$ & $1.9507(23)$ & $2.22(44)$ \\
\hline$C(25)$ & $0.5882(14)$ & $0.3963(4)$ & $1.3366(32)$ & $3.64(53)$ \\
\hline C (26) & $0.3353(13)$ & $0.3027(3)$ & $0.5768(26)$ & $2.71(46)$ \\
\hline$C(27)$ & $0.8019(13)$ & $0.3675(3)$ & $1.3221(29)$ & $3.36(48)$ \\
\hline C (28) & $0.7214(13)$ & $0.3613(4)$ & $1.1794(28)$ & $3.27(48)$ \\
\hline C (29) & 0.2832 (12) & $0.3414(5)$ & $0.8468(40)$ & $4.88(66)$ \\
\hline$C(30)$ & $0.8248(12)$ & 0.4139 (4) & $1.7788(27)$ & $3.06(50)$ \\
\hline$C(31)$ & $0.4560(15)$ & $0.3113(4)$ & $0.6021(28)$ & $3.57(53)$ \\
\hline C (32) & $0.2202(14)$ & $0.2637(4)$ & $0.3780(32)$ & $3.47(52)$ \\
\hline$C(33)$ & 0.9850 (13) & 0.4478 ( 3$)$ & $2.3102(25)$ & $2.59(45)$ \\
\hline C (34) & $0.2285(17)$ & $0.2333(4)$ & $0.2647(31)$ & $4.15(57)$ \\
\hline C (35) & $0.3462(16)$ & $0.2453(4)$ & $0.6450(30)$ & $3.60(53)$ \\
\hline C (36) & $1.0438(12)$ & $0.4287(4)$ & $2.1931(24)$ & 2.57 (44) \\
\hline C (37) & $0.8765(14)$ & $0.4571(3)$ & $2.2595(26)$ & $2.72(48)$ \\
\hline C (38) & $1.0280(18)$ & $0.4630(4)$ & $2.5046(32)$ & $4.58(65)$ \\
\hline C (39) & $0.7252(13)$ & $0.4503(3)$ & 1.9949 (29) & $3.00(47)$ \\
\hline$C(40)$ & $1.1890(19)$ & $0.4283(5)$ & $2.4758(31)$ & $5.10(69)$ \\
\hline C (41) & $0.3588(20)$ & $0.2133(5)$ & 0.5444 (37) & $5.29(72)$ \\
\hline C (42) & $1.2396(24)$ & $0.4355(8)$ & $2.1002(53)$ & $7.45(89)$ \\
\hline C (43) & $1.1622(16)$ & 0.4224 (4) & 2.2500 (28) & $4.05(56)$ \\
\hline C (44) & $0.2505(21)$ & $0.2061(5)$ & $0.4178(42)$ & $5.49(80)$ \\
\hline C (45) & $0.5337(21)$ & $0.4417(6)$ & $1.6702(39)$ & $6.38(81)$ \\
\hline C (46) & $0.5267(22)$ & $0.4707(6)$ & $1.5210(49)$ & $7.16(95)$ \\
\hline C (47) & $1.2396(31)$ & $0.4677(12)$ & $2.1100(72)$ & $10.99(99)$ \\
\hline
\end{tabular}


$\mathrm{C}_{33} \mathrm{H}_{38} \mathrm{~N}_{4} \mathrm{O}_{6}=586.2784$. Anal. Calcd for $\mathrm{C}_{33} \mathrm{H}_{38} \mathrm{~N}_{4} \mathrm{O}_{6} \cdot \mathrm{HCl} \cdot 3 \mathrm{H}_{2} \mathrm{O}$, C; 58.53, H; 6.70, N; 8.27, Cl; 5.23. Found: C, 58.59, H; 6.43, N; 8.30, Cl; 5.34.

c) Determination of Optical Purity: 1) ${ }^{1} \mathrm{H}-\mathrm{NMR}$ : 6-27 or (RS)-6-27 $(10 \mathrm{mg})$ was dissolved in $\mathrm{CDCl}_{3}(5 \mathrm{ml})$, and the shift reagent $(13.6 \mathrm{mg})$ was dissolved in $\mathrm{CDCl}_{3}(2 \mathrm{ml})$. To the solution of 6-27 or $(R S)-6-27(0.5 \mathrm{ml})$, the shift reagent solution $(0.1 \mathrm{ml})$ was added.

2) Liquic Chromatography; CPT-11 or (RS)-CPT-11 (10 mg) was dissolved in $\mathrm{CHCl}_{3}-\mathrm{EtOH}(4: 1,50 \mathrm{ml})$ and $20 \mu \mathrm{l}$ of the solutions were used for HPLC operation with a UV deterctor (wave length: $254 \mathrm{~nm}$ ) and CHIRALCEL OD column $(4.6 \mathrm{~mm} \times 25 \mathrm{~cm}$, Daicel Chem. Ind. Co., Osaka Japan) at $40^{\circ} \mathrm{C}$. A mixture of $n-\mathrm{C}_{6} \mathrm{H}_{14}-\mathrm{EtOH}(1: 1)$ containing $0.2(\mathrm{v} / \mathrm{v}) \%$ of diethylamine was used as an eluent at $1 \mathrm{ml} / \mathrm{min}$. (RS)-CPT-11 revealed two peaks at $11.8 \mathrm{~min}$ and $16.7 \mathrm{~min}$, whereas, CPT-11 prepared by the method described above showed one peak at $16.7 \mathrm{~min}$.

\section{References}

1) A part of this study was presented: S. Sawada, K. Nokata, S. Okajima, T. Furuta, T. Yokokura, M. Mutai, E. Sugino and T. Miyasaka, Poster Abstractr. at the Japanese-United States Congress of Pharmaceutical Sciences, 1987, Honolulu, Hawaii, Dec. 1987, p. 166 and S. Sawada, K. Nokata and T. Miyasaka, p. 172.

2) M. E. Wall, M. C. Wani, C. E. Cook, K. H. Palmer and G. A. Sim, J. Am. Chem. Soc., 88, 3888 (1966).

3) Recent review on camptotheca alkaloids; J.-C. Cai and C. R. Hutchingson, "The Alkaloids," Vol. 21, ed. by A. Brossi, Academic Press, New York, 1983, p. 101 and references cited herein.

4) K. Nitta, T. Yokokura, S. Sawada, T. Kunimoto, T. Tanaka, N Uehara, H. Baba, M. Takeuchi, T. Miyasaka and M. Mutai, ed, by J. Ishigami, "Recent Advances in Chemotherapy, Antitumor Section I, The Proceedings of the 14th International Congress of Chemother.,
Tokyo Univ. Press, Tokyo, 1985, p. 29.

5) a) Phase I trial of CPT-11: T. Taguchi, A. Wakui, H. Niitani, H. Furue, K. Ohta and T. Hattori, Jpn. J. Cancer Chemother., 17, 115 (1990); b) Phase II trial of CPT-11 (non-small cell lung cancer): $M$. Fukuoka, S. Negoro, H. Niitani and T. Taguchi, 1990 American Society of Clinical Oncology, Annual Meeting, Washington D. C., May 1990.

6) T. Miyasaka, S. Sawada and K. Nokata, Heterocycles, 16, 1713, 1719 (1981).

7) a) Y.-H. Hsing, R. Hertbeg, S. Hecht and L.-F. Liu, J. Biol. Chem., 27, 14873, (1985); b) Y. Kawamoto, K. Yasuoka, K. Matsumoto and M. Tomikawa, Proceedings of the Japanese Cancer Association, 46th Annual Meeting, Tokyo, 1987, p. 408; c) T. Andoh, K. Ishii, Y. Suzuki, Y. Ikegami, Y. Kusunoki, Y. Takemoto and K. Okada, Proc. Natl. Acad. Sci., U.S.A., 84, 5565 (1987).

8) E. Heymann, "Metabolic Basis of Detoxication," ed. by W. B. Jakoby, J. R. Bend and J. Caldwell, Academic Press, New York, 1982 , p. 229

9) A. A. Sinkula and S. H. Yalkowsky, J. Pharm. Sci., 64, 181 (1975) and references cited herein.

10) a) N. B. Chapmann, K. Clarke and K. Wilson, J. Chem. Soc., 1963, $2256 ; b)$ B. Hermans, P. van Daele, C. van de Westeringh, C. van der Eycken, J. Boey and P. A. J. Janssen, J. Med. Chem., 9, 49 (1966).

11) A. T. McPhail and G. A. Sim, J. Chem. Soc. (B), 1968, 923.

12) A. Ejima, H. Terasawa, M. Sugimori and H. Tagawa, J. Chem. Soc. Perkin Trans. 1, 1990, 27.

13) M. C. Wani, P. E. Ronman, J. T. Lindley and M. E. Wall, J. Med. Chem., 23, 554 (1980).

14) N. Kaneda, H. Nagata, T. Furuta and T. Yokokura, Cancer Res., 50, 1715 (1990). 